\title{
Cancer-Associated Fibroblasts Accelerate Malignant Progression of Non-Small Cell Lung Cancer via Connexin 43-Formed Unidirectional Gap Junctional Intercellular Communication
}

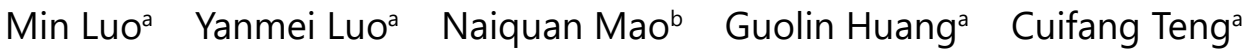 \\ Hanlin Wang ${ }^{c}$ Junwei Wu ${ }^{b}$ Xiaoli Liao ${ }^{d}$ Jie Yang ${ }^{a}$ \\ aDepartment of Pharmacology, School of Pharmacy, Guangxi Medical University, Nanning, bDepartment \\ of Thoracic Surgery, Affiliated Cancer Hospital, Guangxi Medical University, Nanning, 'Department \\ of Internal Medicine, First Affiliated Hospital, Guangxi Medical University, Nanning, dDepartment of \\ Chemotherapy, Affiliated Cancer Hospital, Guangxi Medical University, Nanning, China
}

\section{Key Words}

Connexin 43 - Unidirectional gap junctional intercellular communication - Cancer-associated fibroblasts • Non-small cell lung cancer • Metabolic coupling • Malignant progression

\footnotetext{
Abstract

Background/Aims: Gap junctions, which are assembled by connexins, can directly connect the cytoplasm of adjacent cells and enable gap junctional intercellular communication (GJIC) as well as metabolic coupling between neighboring cells. Here, we investigated the role of connexin $43(\mathrm{C} \times 43)$ and its derived GJIC in the interplay between non-small cell lung cancer (NSCLC) cells and cancer-associated fibroblasts (CAFs). Methods: CAFs and NSCLC cells were co-cultured with direct contact and separated using flow cytometry. Glucose uptake, lactate production, and the expression and activity of PKM-2 and LDH-A in sorted CAFs were measured by a colorimetric assay, western blotting, and enzyme-linked immunosorbent assay (ELISA). Meanwhile, E-cadherin and $\mathrm{N}$-cadherin expression and the migration and invasion of sorted NSCLC cells were detected by western blotting, wound width, and Transwell assays. Pyruvate, acetyl-CoA, and citric acid levels, ATP levels, and LDH-B and $\alpha-K G$ activity in sorted NSCLC cells were determined by a colorimetric or fluorometric assay and ELISA, respectively. Functional GIC between cells and the subcellular location of connexins were detected by a "Parachute" assay and immunofluorescence. Levels of $\alpha-S M A, C x 43$, and LDH-B in tissue from patients with NSCLC were determined by immunohistochemistry. Results: $\mathrm{Cx} 43$ accumulated in the plasma membrane, which favored the assembly of asymmetric unidirectional GJIC from CAFs to NSCLC cells. CAFs underwent increased aerobic glycolysis and promoted

M. Luo, Y. Luo and N. Mao contributed equally to this work. 
the epithelial-mesenchymal transition, migration, and invasion of NSCLC cells. In contrast, NSCLC cells experienced enhanced oxidative phosphorylation upon CAF stimulation, with an increase in ATP generation and thereby activation of the PI3K/Akt and MAPK/ERK pathways. Metabolic coupling between CAFs and NSCLC cells was under the strict control of Cx43formed unidirectional GJIC. Patients with high tri-expression of $\alpha$-SMA, Cx43, and LDH-B had the shortest overall survival and relapse-free survival compared with those with individual overexpression or high bi-expression. Conclusion: Cx43-formed unidirectional GJIC plays a critical role in mediating close metabolic cooperation between CAFs and NSCLC cells to support the malignant progression of NSCLC.

(C) 2018 The Author(s)

Published by S. Karger AG, Basel

\section{Introduction}

Non-small cell lung cancer (NSCLC) is one of the most prevalent forms of lung cancer and the leading cause of cancer death [1]. Most patients with NSCLC are initially diagnosed at an advanced stage and therefore have poor prognosis [2]. Although recent advances in early detection and targeted therapies have yielded improvements in the outcome of NSCLC patients, the 5-year survival rate remains less than 15\% [3]. Therefore, there is an urgent need to explore new and more effective targets against the malignant progression of NSCLC.

Cancer-associated fibroblasts (CAFs), a major cellular component of the tumor microenvironment in most solid cancers, are key determinants in regulating the malignant progression of cancer [4]. Indeed, CAFs have already been proven to promote epithelialmesenchymal transition (EMT), invasion, and metastases in several cancer models, including NSCLC $[5,6,7]$. Intriguingly, the "reverse Warburg effect" of CAFs, which is deeply involved in cancer malignancy, has been increasingly revealed in recent years. In contrast to the classic "Warburg effect" [8], Pavlides et al. proposed a new model, termed the reverse Warburg effect, in which epithelial cancer cells induce the Warburg effect (i.e., aerobic glycolysis) in surrounding CAFs and thereby turn them into factories for the production of energy-rich metabolites to feed epithelial cancer cells directly in a host-parasite pattern [9]. In direct support of this notion, CAFs switch their metabolism to aerobic glycolysis, while prostate cancer cells are reprogrammed toward aerobic metabolism to sustain their energetic needs and growth [10]. Contradictorily, CAF-derived exosomes could inhibit mitochondrial oxidative phosphorylation (OXPHOS) in prostate cancer cells, thereby increasing glycolysis and glutamine-dependent reductive carboxylation and promoting tumor growth [11]. However, the precise functional contribution of CAFs to the metabolic orchestration between NSCLC and the tumor microenvironment remains poorly understood.

Connexins are a homologous family of more than 20 transmembrane proteins [12]. Six connexins oligomerize to form a connexon, which can assemble at the plasma membrane to form either functional hemichannels or gap junctions [13]. Gap junctions can directly connect the cytoplasm of neighboring cells, thereby allowing the direct exchange of small substances with a molecular weight of up to $1.5 \mathrm{kDa}$, such as ions, second messengers, peptides, nucleotides, and metabolic molecules [14]. This process is termed gap junctional intercellular communication (GJIC). Although connexins and their derived GJIC have long been considered tumor suppressors over the past 50 years $[15,16,17]$, growing evidence suggests that they also contribute to malignant progression during the late stages of some cancer types $[13,15,18]$. In particular, heterocellular GJIC between cancer cells and adjacent cells, such as endothelial cells, mesothelial cells, osteoblastic cells, and astrocytes, has been demonstrated to play a crucial role in facilitating cancer invasion and metastasis $[19,20,21$, $22,23,24]$. Moreover, asymmetric heterologous GJIC has been observed from normal lung fibroblasts to human lung carcinoma cells [25]. In addition, GJIC has been known to mediate not only intercellular communication but also metabolic coupling between neighboring cells $[26,27]$. However, it remains unclear whether GJIC exists between CAFs and NSCLC cells and 
whether GJIC is involve in the metabolic cooperation between CAFs and NSCLC cells. The aim of this study was to investigate the role of connexin 43 (Cx43) and its derived GJIC in the metabolic coupling between NSCLC cells and CAFs.

\section{Materials and Methods}

\section{Reagents and antibodies}

The catalog numbers and concentrations of the antibodies used in this study are shown in Table 1. All-trans-retinoic acid (RA) was purchased from Merck (San Diego, CA, USA). Lactate dehydrogenase isoform B (LDH-B), LDH-A, pyruvate kinase muscle 2 (PKM-2), and $\alpha$-ketoglutarate ( $\alpha$-KG) enzyme-linked immunosorbent assay (ELISA) kits were purchased from CUSABIO Technology (Wuhan, China). A pyruvate, ATP, acetyl-coenzyme A (acetyl-CoA), and citric acid assay kit was purchased from Solarbio (Beijing, China). All other reagents were from Sigma (St. Louis, MO, USA) unless stated otherwise.

\section{Cell culture}

Human high invasive potential NSCLC cells A549 and H1299 were from the American Type Culture Collection (Manassas, VA, USA) and cultured in RPMI 1640 (Gibco, Carlsbad, CA, USA) supplemented with $10 \%$ fetal bovine serum and antibiotics. By using a study protocol approved by the Guangxi Medical University Ethics Committee (IRB no. 20140304-003), CAFs and their paired normal fibroblasts (NFs) were isolated from 7 surgically resected primary NSCLCs and corresponding adjacent normal lung tissues obtained at least $5 \mathrm{~cm}$ from the outer tumor margin, respectively [28]. NFs and CAFs were maintained in DMEM supplemented with $10 \%$ fetal bovine serum (Gibco) and antibiotics $(100 \mathrm{U} / \mathrm{mL}$ penicillin and 100 $\mu \mathrm{g} / \mathrm{mL}$ streptomycin).

\section{Collagen gel contraction assay}

The contractility of CAFs was measured according to the method described by Horie et al [29]. and Navab et al. [30]. Briefly, suspended CAFs or NFs, collagen gel (Sigma), distilled water, and DMEM were mixed gently. The volumes of the mixtures were adjusted so that cell density was $2.0 \times 10^{5}$ cells $/ \mathrm{mL}$ and the collagen concentration was $1 \mathrm{mg} / \mathrm{mL}$. The mixtures $(0.5 \mathrm{~mL})$ were subsequently inoculated into each well of a 24-well plate. Collagen gel contraction occurred in $30 \mathrm{~min}$ at $37^{\circ} \mathrm{C}$ and was initiated by detaching the edges of the collagen gels from the sides of the wells. The collagen gels were then transferred to another 24well plate containing $0.5 \mathrm{~mL}$ medium in each well and placed in an incubator. The area of the collagen gels was determined after 24,48 , and $72 \mathrm{~h}$ using an image analysis system (inverted fluorescence microscope, TS100-F; Nikon, Tokyo, Japan). The diameters of the collagen gels were measured in mm and recorded as the average values of the major and minor axes.

Table 1. Catalogue numbers and concentrations of the antibodies

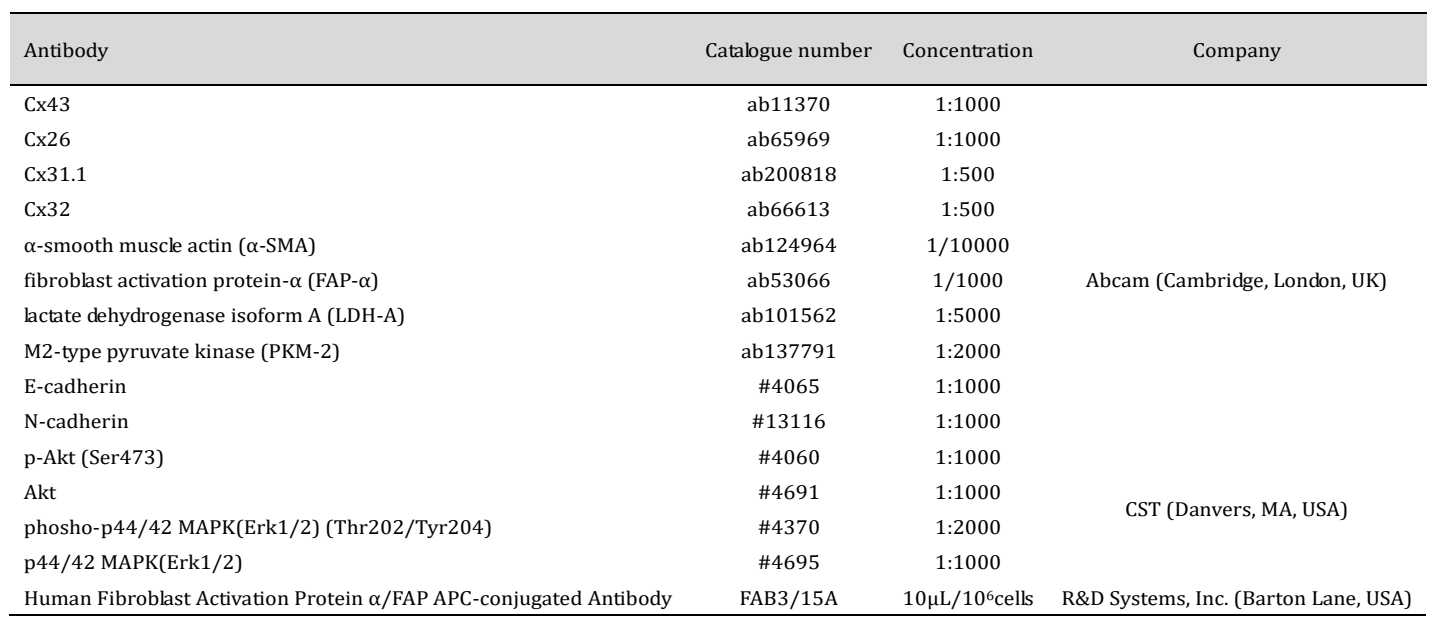




\section{Cellular Physiology Cell Physiol Biochem 2018;51:315-336 and Biochemistry \begin{tabular}{l|l} 
DOI: 10.1159/000495232 & $\begin{array}{l}\text { (c) } 2018 \text { The Author(s). Published by S. Karger AG, Basel } \\
\text { www.karger.com/cpb }\end{array}$
\end{tabular}

Luo et al.: Cafs Accelerate NSCLC Malignant Progression

\section{Patients}

This study was a retrospective analysis involving 82 patients with NSCLC diagnosed at the Affiliated Cancer Hospital of Guangxi Medical University (Nanning, China) between December 24, 2012, and November 14,2014 . The inclusion criteria were patients with primary NSCLC of tumor stages IA to IVA who underwent surgery as the initial treatment modality and had complete clinicopathological data. Eighty-two patients were followed up until September 27, 2016. Time to recurrence was the time from the date of surgery to the date of radiological recurrence. The study design was approved by the Guangxi Medical University Ethics Committee (IRB no. 20140304-003), and signed informed consent was obtained from all patients.

\section{Co-culture system and cell sorting}

For direct contact co-culture, CAFs and NSCLC cells were mixed to a total number of $1.0 \times 10^{6}$ cells at a 5:1 ratio for 3 days. After the cells were collected, CAFs were labeled with a phycoerythrin-labeled antifibroblast activation protein alpha (FAP- $\alpha$ ) antibody for $30 \mathrm{~min}$ at $4^{\circ} \mathrm{C}$ in the dark. Fluorescent cells were identified as FAP- $\alpha$-labeled CAFs, and non-fluorescent cells were identified as cancer cells [31], and then cultured for further expression analysis. For the studies involving inhibition or enhancement of glycolysis, CAFs were exposed to 2-deoxy-d-glucose (2-DG, $25 \mathrm{mmol} / \mathrm{L}$ ) or fructose-1, 6-bisphosphate (FBP, 125 $\mathrm{mmol} / \mathrm{L}$ ) for $24 \mathrm{~h}$ before co-cultured with NSCLC cells.

RNA interference and Cx43 overexpression

Three RNA interference sequences targeting Cx43 mRNA (\#Cx43-homo-721: 5'-GGTTGCTGCGAACCTACATCA-3'; \#Cx43-homo-926: 5'-GGTGTCCCTGGCCTTGAATAT-3'; and \#Cx43-homo-1202: 5'-GGCTAATTACAGTGCAGAACA-3') and a one off-target control sequence (\#NC: 5'-TTCTCCGAACGTGTCACGT-3') were cloned separately into the LV10 (U6/RFP\&Puro) vector (GenePharma, Shanghai, China). The LV8 (EF1a-RFP/Puro) vector (GenePharma) containing Cx43 and an empty lentiviral vector as a negative control were used. The cells were transfected with lentiviral vectors using Lipofectamine 2000 (Invitrogen,Carlsbad, CA, USA) according to the manufacturer's instructions. The cells were pooled and analyzed for $\mathrm{Cx} 43$ knockdown or overexpression by western blotting.

Quantitative real-time PCR, western blotting, "Parachute" dye-coupling, and immunofluorescence assays These assays were performed according to our previous report [32].

Cell migration and invasion assay

A cell migration and invasion assay was performed according to our previous study [33].

\section{Cell proliferation and apoptosis assays}

Cell proliferation was measured using 3-(4, 5-dimethylthiazol-2yl-2, 5-diphenyl tetrazolium bromide (MTT) assay, as reported previously [34]. To measure apoptosis, the proportion of apoptotic cells was determined by manually counting pyknotic nuclei after 4',6-diamidino-2-phenylindole (DAPI; Roche, Mannheim, Germany) staining [35]. After $24 \mathrm{~h}$ incubation, DAPI-stained pyknotic nuclei were counted as the percentage of 100 cells in each well.

\section{Activity assays}

Glucose uptake and lactate, pyruvate, acetyl-CoA, citric acid, and ATP production were measured with a colorimetric or fluorometric assay kit according to the manufacturer's instructions. The activity of LDH-A, LDH-B, PKM-2, and $\alpha-$ KG was measured by ELISA.

\section{Immunohistochemistry}

Para-carcinoma tissues were taken at least $2 \mathrm{~cm}$ from the cancerous node. Tissue sections were immunostained with anti-alpha smooth muscle actin ( $\alpha$-SMA), anti-LDH-B, and anti-Cx43 antibodies. A scoring system was used to describe both the staining intensity (negative, weak, moderate, or strong) and the proportion of tumor cells (Cx43: $0 \%,<10 \%, 10-50 \%$, or $>50 \%$; $\alpha$-SMA: $<5 \%, 5-25 \%, 26-50 \%$, or $>50 \%$; LDH-B: $0 \%,<10 \%, 10-50 \%$, or $>50 \%$ ) stained in each case as described previously $[36,37,38]$. An 


\section{Cellular Physiology Cell Physiol Biochem 2018;51:315-336 \begin{tabular}{ll|l} 
and BiOChemistry & DOl: 10.1159/000495232 & $\begin{array}{l}\text { (c) } 2018 \text { The Author(s). Published by S. Karger AG, Basel } \\
\text { www.karger.com/cpb }\end{array}$ \\
\hline
\end{tabular} \\ Luo et al.: Cafs Accelerate NSCLC Malignant Progression}

immunohistochemistry score was then assigned to each sample by multiplying the proportion score and intensity score. An immunohistochemistry score $\geq 3(++,+++)$ was defined as the overexpression of $\alpha$-SMA, LDH-B, and Cx43. The immunohistochemistry slides were reviewed independently by two pathologists.

\section{Statistical analysis}

Statistical analyses were performed using SPSS20.0 (SPSS, Inc., Chicago, IL, USA). Values are presented as the mean \pm standard deviation (SD). Experimental results were evaluated statistically using Student's t test or chi squared test. Survival probabilities were calculated using the Kaplan-Meier method. Independent prognostic factors were evaluated by univariate and multivariable Cox proportional hazards regression analysis. Significance was set at $P<0.05$.

\section{Results}

\section{Cultured CAFs exhibit characteristics of activated fibroblasts (myofibroblasts)}

As shown in Fig. 1A and 1B, CAFs displayed spindle-shaped, flattened, and fibroblastlike morphology similar to NFs. The expression of $\alpha$-SMA and FAP- $\alpha$ was generally much stronger in CAFs than in matched NFs. This increased expression of $\alpha$-SMA and FAP- $\alpha$ was maintained in the initially characterized CAFs for up to 5 passages in vitro (data not shown). Moreover, an increased contractile ability was observed in 2 independently isolated CAFs in passage 1 and passage 5 when compared with their counterpart NFs (Fig. 1C). These results indicated that cultured CAFs can maintain the phenotypic properties of myofibroblasts even without continuing interactions with cancer cells.

CAFs undergo aerobic glycolysis and promote the migration and invasion of NSCLC cells by inducing EMT

CAFs have been reported to undergo aerobic glycolysis (i.e., the reverse Warburg effect) upon activation in response to their interplay with cancer cells [9, 39]. As shown in Fig. 2A and 2B, Fig. S1A and S1B (For all supplemental material see www.karger.com/ $10.1159 / 000495232 /$ ), glucose uptake, lactate production, and the expression and activity of PKM-2 and LDH-A (two key enzymes of aerobic glycolysis) were significantly increased in CAFs co-cultured with A549 or H1299 cells compared with CAFs alone. Pretreatment

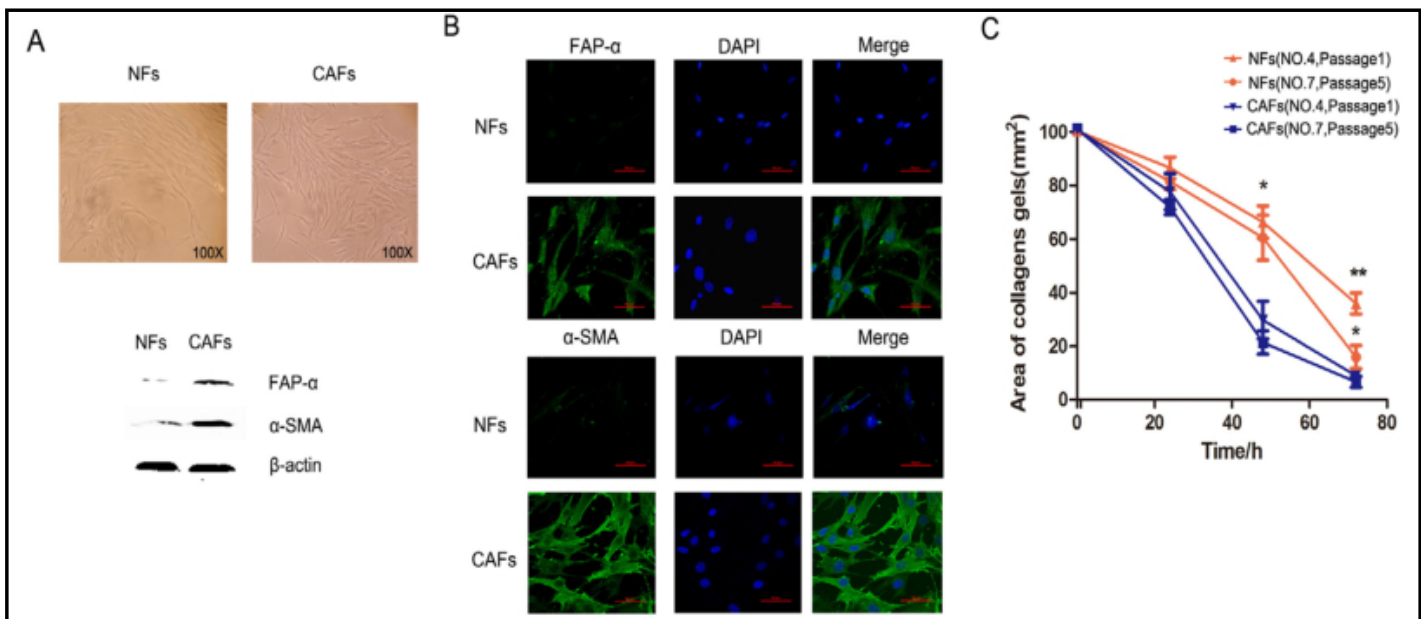

Fig. 1. Characterization of primary CAFs and paired NFs. (A) Morphology of CAFs and NFs (upper). Original magnification, 100x. The expression of FAP- $\alpha$ and $\alpha$-SMA in CAFs and NFs was determined by western blot analysis (bottom). (B) The expression of FAP- $\alpha$ and $\alpha$-SMA in CAFs and NFs was determined by immunofluorescence analysis (scale bar: $50 \mu \mathrm{m}$ ). (C) Time-dependent collagen gel contraction induced by 2 different pairs of NFs and CAFs (NO: case number; passage: passage number). Each point represents the mean \pm SD of 3 replicate samples, ${ }^{*} \mathrm{P}<0.05$, ${ }^{* *} \mathrm{P}<0.01$ compared with paired NFs. 
Fig. 2. CAFs undergo aerobic glycolysis of A549 cells. (A) Glucose uptake and lactate level were measured in mono-cultured and co-cultured CAFs with or without 2-DG or FBP treatment. Data represent the mean $\pm \mathrm{SD}$ of $\mathrm{mg} / \mathrm{dL}$ glucose per $10^{6}$ cells or $\mu \mathrm{g} /$ $\mu \mathrm{L}$ lactate per $10^{6}$ cells from 5 independent experiments. (B) PKM-2 and LDH-A expression and enzymatic activity in CAFs after the indicated treatment were detected by western blotting and ELISA, respectively. (C) The EMT morphology was determined by phase contrast microscopy assays.

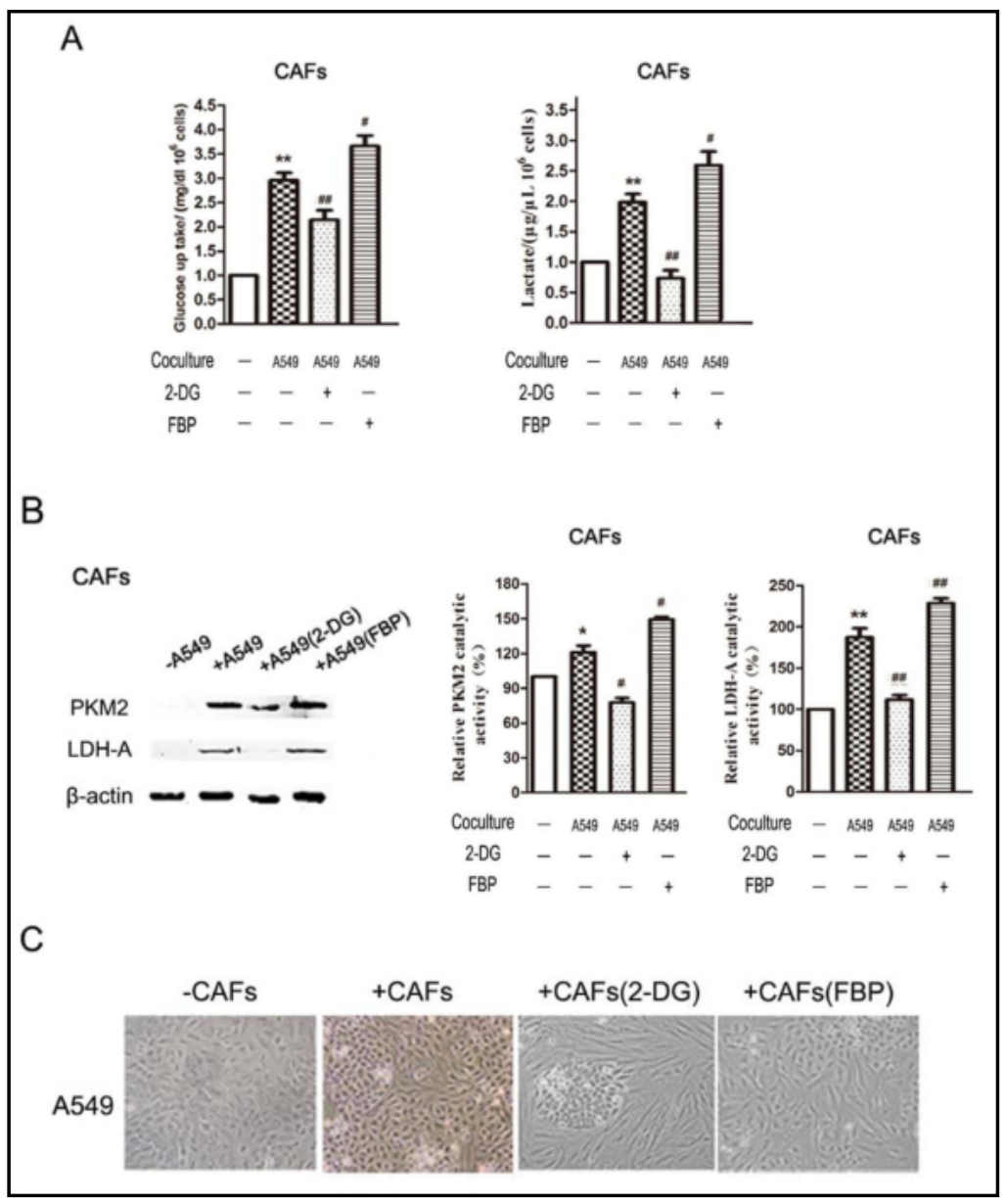

with $125 \mathrm{mmol} / \mathrm{L} \mathrm{FBP}$, a potent activator of PKM-2 [40], greatly enhanced glucose uptake, lactate production, and the expression and activity of PKM-2 and LDH-A in co-cultured CAFs. In contrast, pretreatment with $25 \mathrm{mmol} / \mathrm{L}$ of 2-DG, which is a glycolytic inhibitor, for $24 \mathrm{~h}$ (Fig. 2A and 2B, Fig. S1A and S1B) strongly decreased these glycolytic indexes in co-cultured CAFs. These data suggest that CAFs experience increased aerobic glycolysis upon NSCLC cell activation.

Meanwhile, A549 and H1299 cells lost their epithelial cobblestone appearance and became elongated and dispersed when co-cultured with CAFs (Fig. 2C, Fig. S1C). Consistent with this, the expression of the epithelial marker E-cadherin was downregulated, whereas the expression of the mesenchymal marker N-cadherin was upregulated in co-cultured A549 and H1299 cells (Fig. 3A, Fig. S1D). Mobility and invasive capability were significantly increased in co-cultured A549 and H1299 cells compared with mono-cultured control cells, respectively (Fig. 3B and 3C, Fig. S1E and S1F). Furthermore, preincubation with 2-DG impaired the CAFfacilitated EMT and migration and invasion of co-cultured A549 and H1299 cells, whereas preincubation with FBP strengthened the CAF-promoted effects in these cells (Fig. 2C, Fig. 3A-3C, Fig. S1C-S1F). However, these effects were not attributable to the proliferation and apoptosis of tumor cells (Fig. S1G and S1H). Taken together, these results suggest that CAFs undergo aerobic glycolysis (the reverse Warburg effect) and contribute to the migration and invasion of NSCLC cells via the induction of EMT. 
Aerobic glycolytic CAFS
promote the aggressive
behavior of NSCLC cells via
CX43-formed unidirectional
GJIC
Connexins have long been believed to regulate cancer development and progression by exerting GJIC. Therefore, we next explored whether $\mathrm{Cx} 43$ and its derived GJIC are involved in the CAF-induced progression of NSCLC. As shown in Fig. 4A and Fig. S2A, CAFs, A549 cells, and H1299 cells efficiently transferred calcein to homologous adjacent cells with an average of $10.33 \pm$ 1.53 (SD), $11.33 \pm 3.06$ (SD), and $12.00 \pm 3.61(\mathrm{SD})$ per labeled cell, respectively. Moreover, CAFs showed a high capacity for GJIC with calcein transferred to heterogeneous neighboring A549 or H1299 cells with an average of $20.67 \pm 3.229$ (SD) or $24.00 \pm 2.65$ (SD) per labeled cell, respectively, while A549 and H1299 cells displayed no detectable calcein transfer to CAFs, suggesting that asymmetric unidirectional GJIC is present from CAFs to NSCLC cells.

To understand the basis of the asymmetric heterologous GJIC between CAFs and NSCLC cells, quantitative real-time PCR and western blot analyses were performed to screen for the expression of $\mathrm{Cx} 26, \mathrm{Cx} 31.1, \mathrm{Cx} 32$, and $\mathrm{Cx} 43$ in these cells, which have been reported as the major connexins expressed in mammalian lung tissues or cultured cells $[25,41]$. As shown in Fig. 4B and 4C, Cx26, Cx31.1, Cx32, and Cx43 were differentially expressed in CAFs, A549 cells, and H1299 cells. In particular, Cx26 and Cx43 were the predominant connexin isoforms expressed in these cell lines. Furthermore, Fig. 4D clearly shows that $\mathrm{Cx} 43$ protein accumulated in the plasma membrane of CAFs and in the plasma membrane and cytoplasm of A549 and $\mathrm{H} 1299$ cells, whereas $\mathrm{Cx} 26, \mathrm{Cx} 32$, and Cx31.1 protein accumulated in the cytoplasm of CAFs, A549 cells, and H1299 cells. To confirm further the mediating effect of $\mathrm{Cx} 43$ on unidirectional GJIC from CAFs to NSCLC cells, we transduced lentiviral vectors containing Cx43 short hairpin RNAs (shCx43) or Cx43 into CAFs, A549 cells, and $\mathrm{H} 1299$ cells, respectively (Fig. S2B). Since shCx43-926 was more potent than shCx43-721 and shCx43-1202, we selected the former for the subsequent experiments. A parachute dyecoupling assay showed that knockdown of Cx43 expression in CAFs and/or NSCLC (A549 or H1299) cells significantly abolished GJIC from CAFs and NSCLC cells, while overexpression of $\mathrm{Cx} 43$ in CAFs and/or NSCLC cells resulted in a significant increase in unidirectional GJIC (Fig. 4E, Fig. S2C). Moreover, Cx43 overexpression in both CAFs and NSCLC cells caused a more significant increase in unidirectional GJIC than only overexpression of $\mathrm{Cx} 43$ in CAFs or in A549 or H1299 cells, respectively (Fig. 4E, Fig. S2C). Thus, these data indicate that Cx43 can form functional GJIC from CAFs to NSCLC cells due to its integration into the plasma membrane.

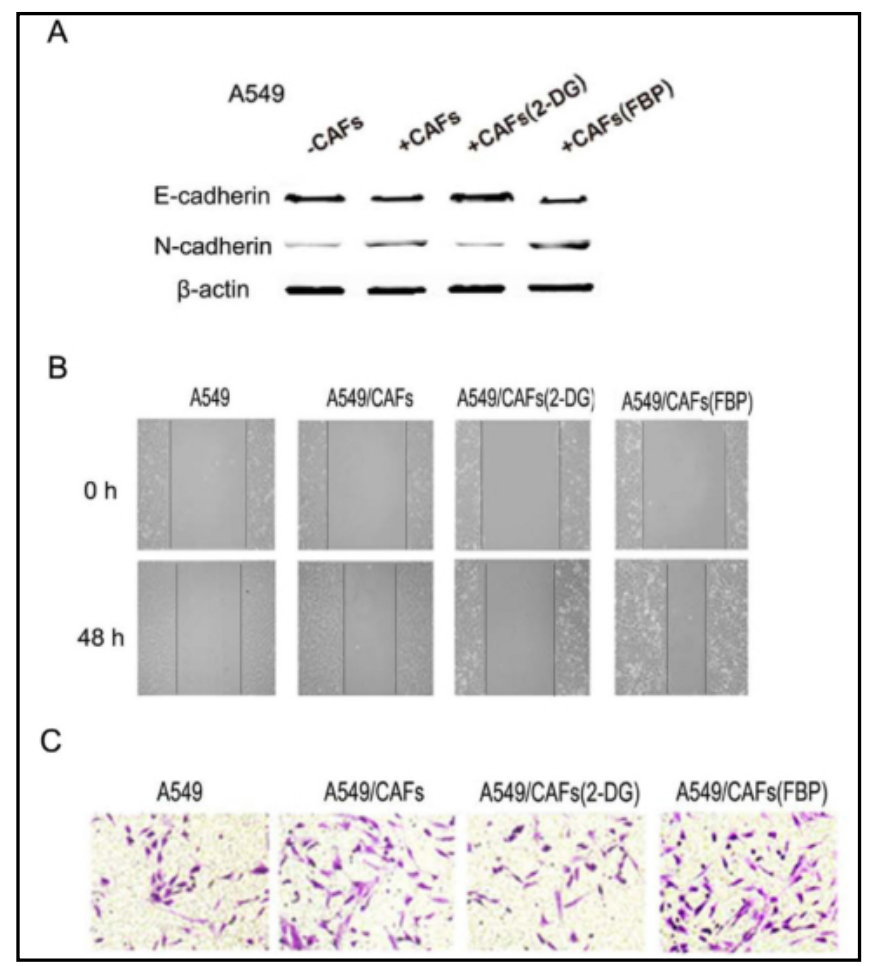

Fig. 3. The EMT marker protein expression (A), and migration (B) and invasion (C) of the indicated NSCLC cells were determined by western blotting, wound healing, and Transwell invasion assays, respectively. Bars are the mean \pm SD from 4 or 5 independent experiments. ${ }^{*} \mathrm{P}<0.05,{ }^{*} \mathrm{P}<0.01$ compared with mono-cultured cells. ${ }^{\#} \mathrm{P}<0.05$, ${ }^{\# \#} \mathrm{P}<0.01$ compared with cocultured A549 cells. Original magnification, morphology: 200x; migration: 100x; invasion: 400x. 
Fig. 4. Cx43-established unidirectional GJIC from CAFs to A549 cells. (A) Functional GJIC was detected by a parachute assay. Top: fluorescence images. Bottom: overlay of the corresponding $\mathrm{p} \mathrm{h}$ a s e - contras t images. Original magnification, 200x. Bars are the mean \pm SD from 5 independent experiments. (B, C) Differential expression of Cx26, Cx31.1, $\mathrm{Cx} 32$, and $\mathrm{Cx} 43$ in CAFs and NSCLC cells was determined by quantitative real-time PCR and western blot. (D) Immunofluorescence staining of the cellular localization of $\mathrm{Cx} 26$, Cx31.1, Cx32, and Cx43 in CAFs and NSCLC cells. All scale bars represent $50 \mu \mathrm{m}$. (E) Functional GJIC between CAFs and A549 cells transfected with shCx43, Cx43 vector, or control empty vectors was detected by a parachute assay. Bars are the mean \pm SD from 4 independent experiments. (F, G) Effects of the GJIC inhibitor $18 \alpha-\mathrm{GA}$ or GJIC enhancer RA on Cx43 protein level and unidirectional GJIC were measured by western blotting and parachute assay, respectively. Bars are the mean \pm SD from 4 independent experiments. ${ }^{* *} \mathrm{P}<0.01$ compared with untreated cells.
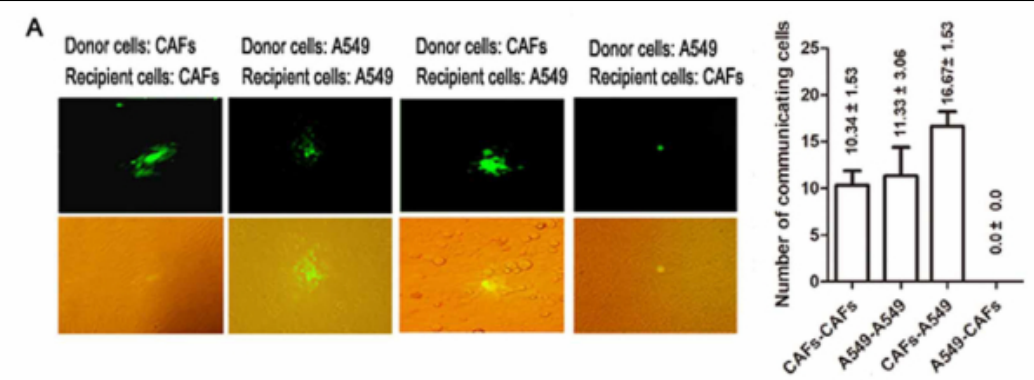

B

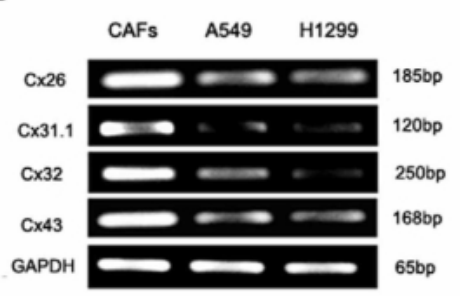

C

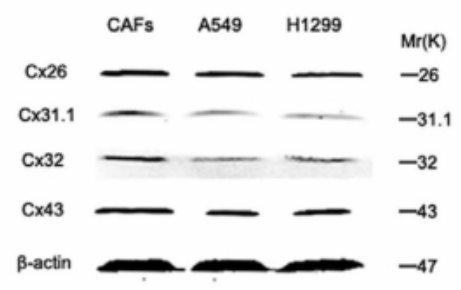

D

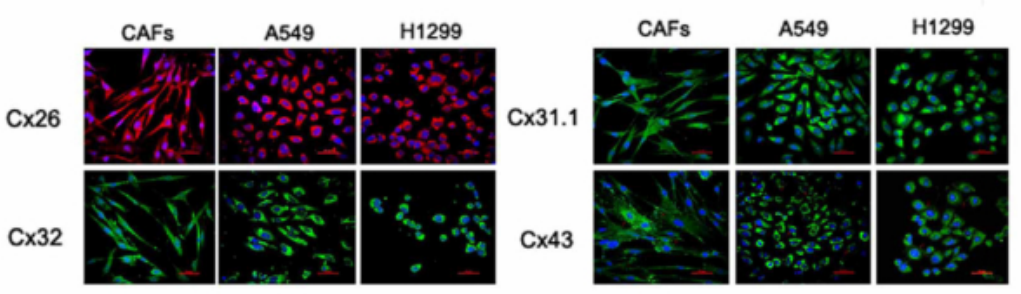

E
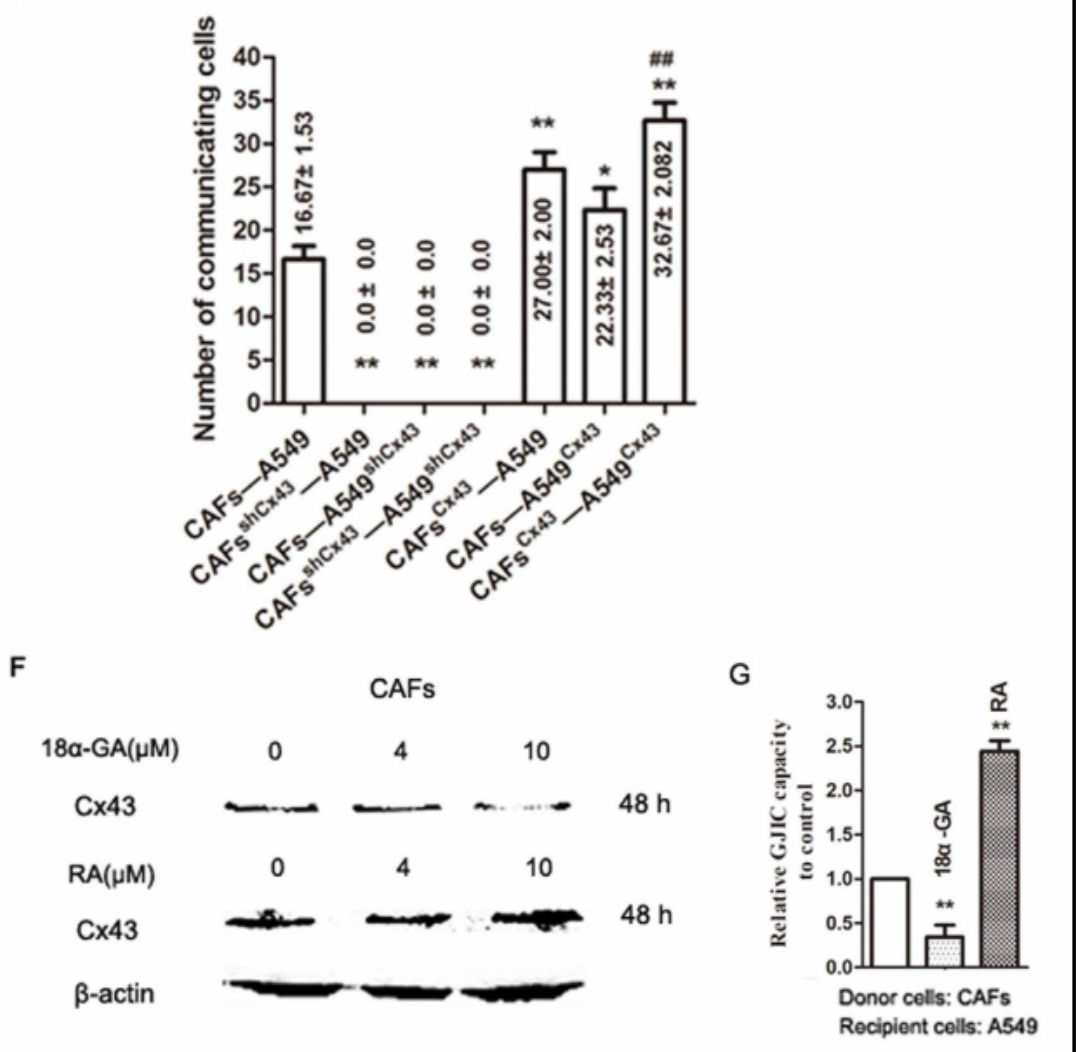
On the basis of the above results, we were interested in exploring whether aerobic glycolytic CAFs promote NSCLC progression in a GJIC-dependent manner. As shown in Fig. 4F$4 \mathrm{G}$ and Fig. S2D, the GJIC inhibitor $18 \alpha$-GA and GJIC enhancer RA ( 4 and $1 \mu \mathrm{M}$, respectively) strongly diminished or elevated Cx43-formed unidirectional GJIC from CAFs to NSCLC cells, respectively, but they did not change $\mathrm{Cx} 43$ protein levels during persistent treatment for up to $48 \mathrm{~h}$. However, inhibition of GJIC by $18 \alpha$-GA (no decrease in Cx43 expression) or shCx43 (Cx43 knockdown) could apparently abrogate the CAF-facilitated EMT, migration, and invasion of co-cultured NSCLC cells to a similar extent (Fig. 5A-5B, Fig. S2E-S2G). On the other hand, enhancement of GJIC in these cells by RA (no increase in Cx43 expression) or lentiviral $\mathrm{Cx} 43$ (Cx43 overexpression) could further strengthen the CAF-induced EMT, migration, and invasion of co-cultured NSCLC cells to a similar degree (Fig. 5A-5B, Fig. S2E$\mathrm{S} 2 \mathrm{G}$ ). Together, these results indicate that $\mathrm{Cx} 43$ is closely implicated in the promoting effects of CAFs on the aggressiveness of NSCLC in a GJIC-dependent manner.

Fig. 5. Cx43-established unidirectional GJIC contributes to the facilitating effect of CAFs on the aggressive behavior of A549 cells. (A, B) Comparison of the effects of $18 \alpha-\mathrm{GA}, \mathrm{Cx} 43$ knockdown, RA, and $\mathrm{Cx} 43$ overexpression on EMT marker expression, and the migration and invasion of A549 cells co-cultured with CAFs. Bars are the mean \pm SD from 4 independent experiments. $\quad * \mathrm{P}<0.05$, **P $<0.01$ compared with cocultured NSCLC cells. (C, D) Comparison of the effects of the glycolytic activator FBP and glycolytic inhibitor 2-DG on EMT marker expression, and the migration and invasion of $\mathrm{Cx} 43$-depleted or Cx43-overexpressing A549 cells co-cultured with the indicated CAFs. Bars are the mean \pm SD from 4 independent experiments. ${ }^{*} \mathrm{P}<0.05$, ${ }^{* *} \mathrm{P}<0.01$ compared with co-cultured A549 cells. ${ }^{\#} \mathrm{P}<0.05$, ${ }^{\# \#} \mathrm{P}<0.01$ compared with Cx43-depleted cocultured A549 cells. ${ }^{\&} \mathrm{P}<0.05$, ${ }^{\&} \mathrm{P}<0.01$ compared with Cx43-overexpressing cocultured A549 cells.

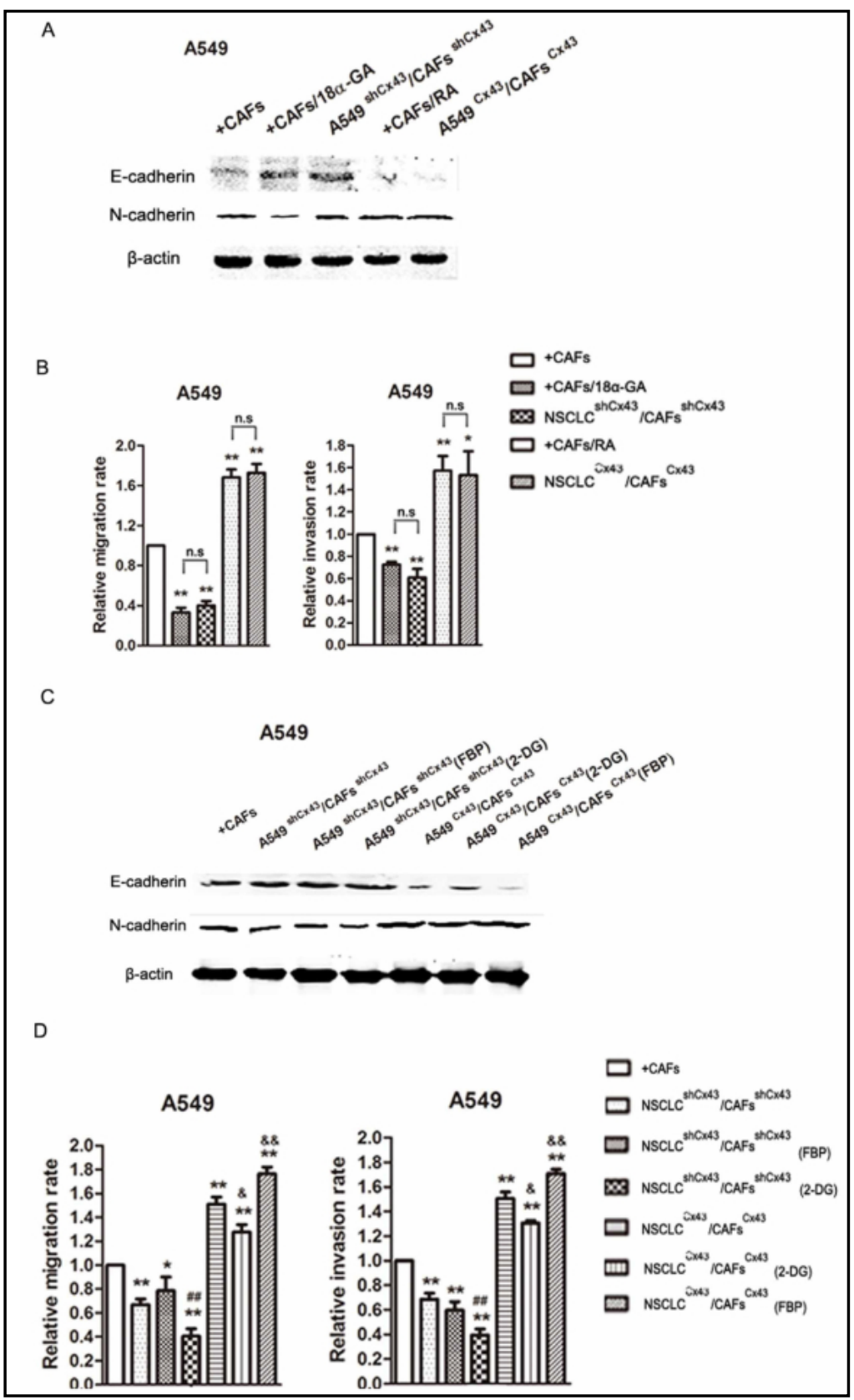


Pretreatment of CAFs with the glycolytic activator FBP could not rescue the impaired EMT phenotype and migratory and invasive potential of GJIC-deficient co-cultured NSCLC cells, whereas pretreatment of CAFs with the glycolytic inhibitor 2-DG worsened the impaired EMT phenotype and migratory and invasive potential of these NSCLC cells (Fig. 5C5D, Fig. S2H-S2J). On the other hand, pretreatment of CAFs with 2-DG only partially reversed the increased EMT, migration, and invasion of GJIC-enhanced co-cultured NSCLC cells, while pretreatment of CAFs with FBP could further reinforce the increased EMT, migration, and invasion of GJIC-enhanced co-cultured NSCLC cells (Fig. 5C-5D, Fig. S2H-S2J). Collectively, these results confirm that $\mathrm{Cx} 43$-formed unidirectional GJIC is mainly responsible for the proEMT/invasive/migratory effects of aerobic glycolytic CAFs on NSCLC cells.

\section{NSCLC cells shift metabolism to OXPHOS in response to aerobic glycolytic CAFs through} Cx43-formed unidirectional GJIC

Recent studies have shown that stromal-epithelial metabolic coupling occurs between CAFs and epithelial cancer cells in human breast cancer and prostate cancer [10, 42]. Therefore, we asked whether there exists a metabolism shift in NSCLC cells in response to $\mathrm{CAF}$ induction. First, we found that glucose uptake and lactate production were significantly decreased in mono-cultured A549 and H1299 cells compared with CAFs (Fig. 6A). Moreover, glucose uptake and lactate production were further decreased in A549 and H1299 cells when co-cultured with CAFs (Fig. 6A). Next, we explored whether the reduced lactate level of NSCLC cells was due to its conversion to pyruvate and then the pyruvate is used to fuel

Fig. 6. $\mathrm{CAFs}$ increase OXPHOS in NSCLC cells. (A) Glucose uptake and lactate level were measured in mono-cultured and cocultured NSCLC cells. Data represent the mean \pm SD of $\mathrm{mg} / \mathrm{dL}$ glucose or $\mu \mathrm{g} / \mu \mathrm{L}$ lactate per 106 cells from 5 independent experiments. ${ }^{*} \mathrm{P}<0.05, \quad \quad * * \mathrm{P}<0.01$ compared with CAFs. ${ }^{\# \# P}<0.01$ compared with mono-cultured NSCLC cells. (B, C) Analysis of the relative catalytic activity of LDH-B and levels of pyruvate and acetyl-CoA, citric acid level, relative $\alpha$-KG activity, and ATP production in monocultured and co-cultured A549 cells with or without 2-DG or FBP treatment. Data represent the mean \pm SD from 4 independent experiments. $\quad * \mathrm{P}<0.05$, ${ }^{* *} \mathrm{P}<0.01$ compared with mono-cultured A549 cells. ${ }^{\#} \mathrm{P}<0.05,{ }^{\# \#} \mathrm{P}<0.01$ compared with cultured A549 cells.

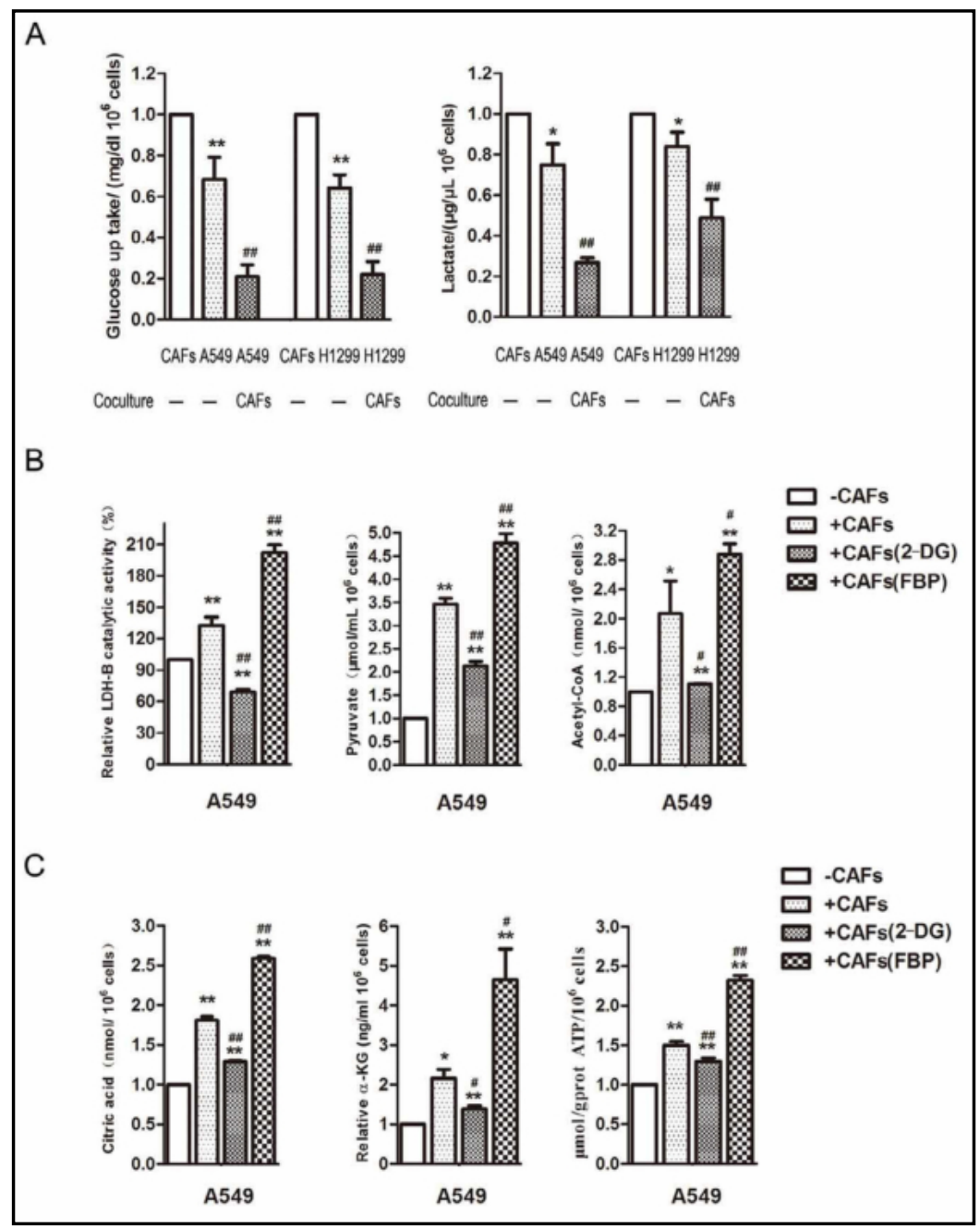


the tricarboxylic acid cycle (TCA) as a useful energy substrate. Interestingly, LDH-B activity and pyruvate and acetyl-CoA levels were markedly increased in A549 and H1299 cells in the presence of CAFs (Fig. 6B). Consistently, the levels of TCA metabolites (citric acid, $\alpha$-KG, and ATP) in A549 and H1299 cells in the presence of CAFs were dramatically higher than in the absence of CAFs (Fig. 6C). In addition, pretreatment of CAFs with the glycolytic inhibitor 2-DG strongly inhibited the increase in LDH-B activity and pyruvate, acetyl-CoA, and TCA metabolite levels in co-cultured A549 cells, while pretreatment of CAFs with the glycolytic activator FBP greatly strengthened the increase in these metabolites in co-cultured A549 cells (Fig. 6B and 6C). The same results were obtained in H1299 cells (data not shown). Thus, these results indicate that NSCLC cells reduce glycolytic metabolism but also enhance OXPHOS in response to CAF stimulation.

Notably, GJIC has been reported to participate in the trafficking of metabolites between astrocytes, which mainly express Cx43 [43]. Thus, we further detected whether Cx43formed unidirectional GJIC is involved in the metabolic coupling between CAFs and NSCLC cells. As seen in Fig. 7, inhibition of GJIC by Cx43 knockdown in both CAFs and A549 cells enhanced the lactate level and reduced LDH-B activity as well as pyruvate, acetyl-CoA, and TCA metabolite levels in co-cultured A549 cells, whereas enhancement of GJIC by Cx43 overexpression in both CAFs and A549 cells reduced the lactate level and enhanced LDH-B activity as well as pyruvate, acetyl-CoA, and TCA metabolite levels in co-cultured A549 cells. Moreover, pretreatment of CAFs with the glycolytic activator FBP did not affect the enhanced lactate level and reduced LDH-B activity or pyruvate, acetyl-CoA, and TCA metabolite levels in GJIC-deficient co-cultured A549 cells, while pretreatment of CAFs with the glycolytic inhibitor 2-DG further enhanced the lactate level and further reduced LDH-B activity as well as pyruvate, acetyl-CoA, and TCA metabolite levels in A549 cells (Fig. 7). 2-DG could partially

Fig. 7. Analysis of the above metabolic indexes in Cx43depleted or Cx43overexpressing A549 cells co-cultured with the indicated CAFs with or without 2-DG or FBP treatment. Data represent the mean \pm SD from 3 independent e $x$ p e r i m e $\mathrm{nt}$ s. * $\mathrm{P}<0.05, \quad * * \mathrm{P}<0.01$ compared with cocultured A549 cells. " $\mathrm{P}<0.05, \quad{ }^{\# \#} \mathrm{P}<0.01$ compared with Cx43-depleted cocultured A549 cells. $\quad$ \& $\mathrm{P}<0.05, \quad \quad$ \& $\mathrm{P}<0.01$ compared with $\mathrm{Cx} 43$ overexpressing cocultured A549 cells.

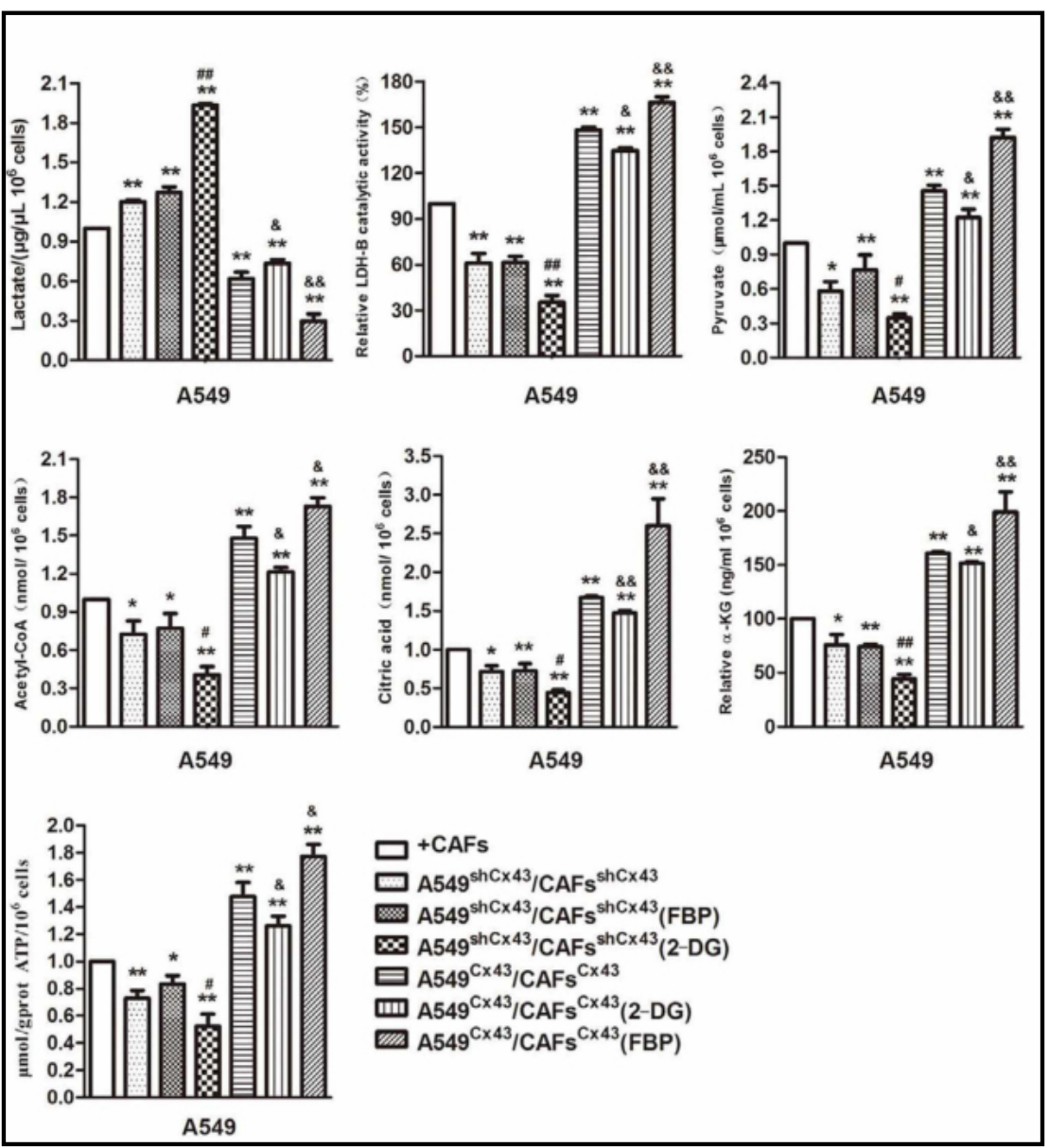


antagonize the CAF-induced decrease in the lactate level and increase in LDH-B activity as well as pyruvate, acetyl-CoA, and TCA metabolite levels in GJIC-enhanced co-cultured A549 cells, while FBP further strengthened these CAF-induced effects in GJIC-enhanced cocultured A549 cells (Fig. 7). Similar effects were observed in H1299 cells (data not shown). Taken together, NSCLC cells enhance OXPHOS upon stimulation of aerobic glycolytic CAFs in a Cx43-formed unidirectional GJIC-dependent manner.

ATP is involved in the CAF-promoted activation of the PI3K/Akt and MAPK/ERK pathways and migration and invasion of NSCLC cells

Since we confirmed above that the level of ATP derived from TCA was substantially elevated in A549 and H1299 cells upon the induction of aerobic glycolytic CAFs (Fig. 6C), we aimed to determine whether ATP levels correlated with the CAF-stimulated migration and invasion of NSCLC cells. As seen in Fig. 8A, phosphorylated Akt and ERK levels were significantly increased in A549 and H1299 cells in the presence of CAFs compared with the absence of CAFs. The glycolytic inhibitor 2-DG partially inhibited the CAF-induced increased of Akt and ERK activity in co-cultured A549 and H1299 cells, while the glycolytic activator FBP further strengthened these CAF-induced effects. Furthermore, inhibition of GJIC by Cx43 knockdown remarkably reduced CAF-enhanced Akt and ERK activity in A549 and H1299 cells, whereas enhancement of GJIC by Cx43 overexpression further increased CAFenhanced Akt and ERK activity in these NSCLC cells (Fig. 8B). However, FBP did not elevate

Fig. 8. ATP A

is involved

in the CAF-

facilitated

effects. (A)

W e s t e r $n$

blot analysis

of Akt with

ERK activity B

in mono-

cultured and

co-cultured

N S C L C

cells with

or without

2-DG or FBP

treatment.

D $a$ t a

represent

the mean \pm

SD from 4

independent

experiments.

$* \mathrm{P}<0.05$,
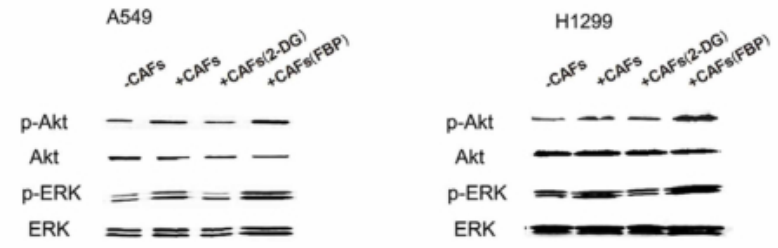

$* * \mathrm{P}<0.01$
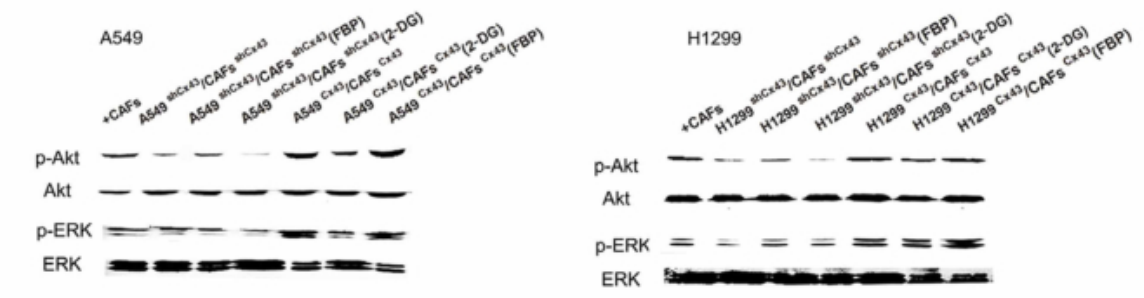

compared with mono-cultured NSCLC cells. ${ }^{\#} \mathrm{P}<0.05$, ${ }^{\# \#} \mathrm{P}<0.01$ compared with co-cultured NSCLC cells. (B) Western blot analysis of Akt and ERK activity in Cx43-depleted or Cx43-overexpressing NSCLC cells co-cultured with the indicated CAFs with or without 2-DG or FBP treatment. Data represent the mean \pm SD from 3 independent experiments. ${ }^{*} \mathrm{P}<0.05$, ${ }^{* *} \mathrm{P}<0.01$ compared with co-cultured NSCLC cells. ${ }^{*} \mathrm{P}<0.05$, ${ }^{\# \#} \mathrm{P}<0.01$ compared with $\mathrm{Cx} 43$-depleted co-cultured A549 cells. ${ }^{\&} \mathrm{P}<0.05$, ${ }^{\&} \mathrm{P}<0.01$ compared with $\mathrm{Cx} 43-$ overexpressing co-cultured A549 cells. (C) Comparison of the effects of LY294002 or U0126 alone or a combination of LY294002 and U0126 on Akt and ERK activity of NSCLC cells with or without ATP treatment. Data represent the mean \pm SD from 3 independent experiments. 
Akt and ERK activity in GJIC-deficient co-cultured A549 and H1299 cells, but 2-DG further depressed Akt and ERK activity in these NSCLC cells (Fig. 5B). In addition, 2-DG partially impaired the CAF-induced increase in Akt and ERK activity in GJIC-enhanced co-cultured A549 or H1299 cells, while FBP further raised the CAF-induced increase in Akt and ERK activity in these NSCLC cells (Fig. 8B). Together, these findings reinforce a GJIC-dependent stimulatory effect of aerobic glycolytic CAFs on the activation of the PI3K/Akt and MAPK/ ERK pathways in NSCLC cells.

Furthermore, additional ATP administration $(100 \mu \mathrm{M}, 12 \mathrm{~h})$ greatly activated the PI3K/ Akt and MAPK/ERK pathways and promoted the migration and invasion of A549 and H1299 cells when compared with untreated control cells (Fig. 8C, 9A-9B). Pretreatment with the PI3K/Akt inhibitor LY294002 (10 $\mu \mathrm{M}, 30 \mathrm{~min})$ or MAPK/ERK inhibitor U0126 (10 $\mu \mathrm{M}, 30$ min) alone led to a similar decrease, and a combination of LY294002 and U0126 caused a synergetic decrease in PI3K/Akt and MAPK/ERK activity and the migration and invasion of A549 and H1299 cells (Fig. 8C, 9A-9B). In contrast, the addition of ATP partially restored the suppressed activity of the PI3K/Akt and MAPK/ERK pathways and the migration and invasion of A549 and H1299 cells after LY294002 and/or U0126 treatment (Fig. 8C, 9A-9B). Thus, these results indicate that ATP is involved in the CAF-facilitated activation of the PI3K/ Akt and MAPK/ERK signaling cascades and the migration and invasion of NSCLC cells.

Fig. 9. Comparison of the effects of LY294002 or U0126 alone or a combination of LY294002 and U0126 on the migratory (A) and invasive (B) potential of NSCLC cells with or without ATP treatment. Data represent the mean \pm SD from 4 independent experiments. ${ }^{*} \mathrm{P}<0.05, \quad{ }^{*} \mathrm{P}<0.01$ compared with control group without any treatment. ${ }^{\#} \mathrm{P}<0.05,{ }^{\# \#} \mathrm{P}<0.01$ compared with corresponding group without ATP treatment. ${ }^{\&} \mathrm{P}<0.05$, \&\& $\mathrm{P}<0.01$ compared with corresponding group with LY294002 or U0126 treatment alone.

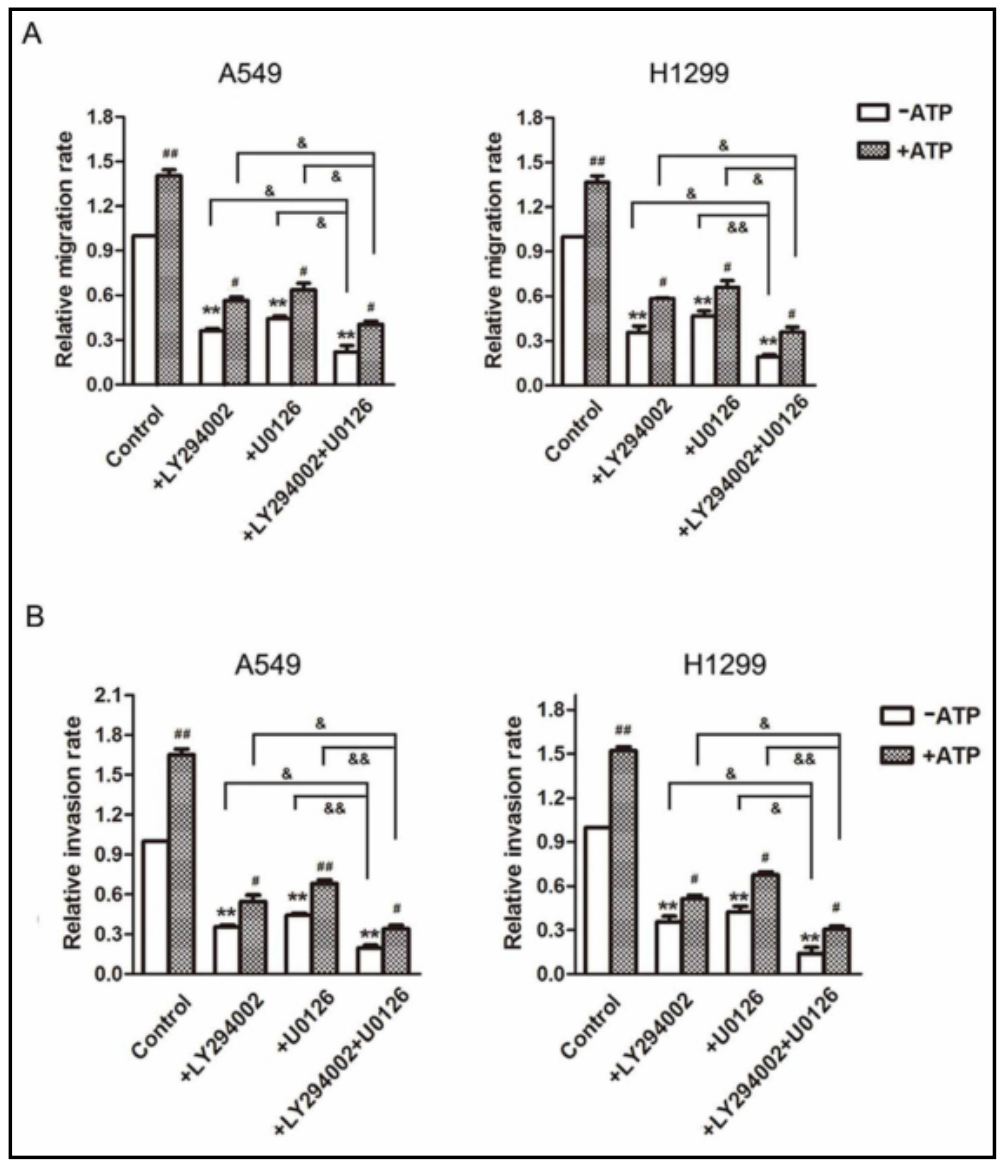




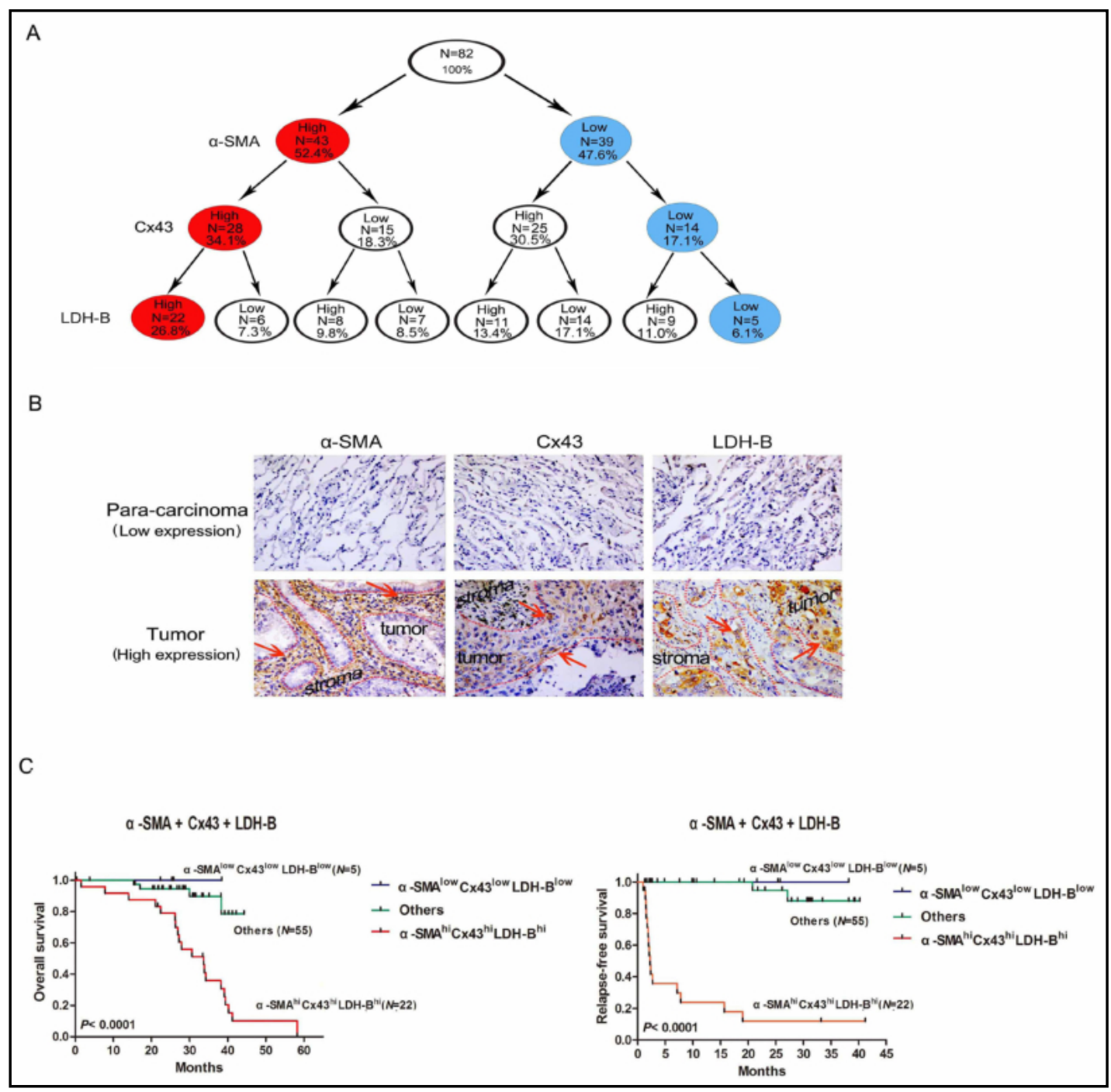

Fig. 10. Clinical significance of $\alpha-S M A, L D H-B$, and $C x 43$ for primary NSCLC patients. (A) Tree diagram showing the proportions of patients with high and low levels of $\alpha$-SMA, LDH-B, and Cx43. (B) Immunohistochemical staining of $\alpha$-SMA in CAFs, LDH-B in NSCLC cells, and Cx43 in both CAFs and NSCLC cells from serial sections of tumor specimens obtained from a clinical cohort of 82 patients with primary NSCLC who underwent surgical resection. The images were obtained from different patients with low (score < median risk score) and high (score $\geq$ median risk score) expression of $\alpha$-SMA, LDH-B, and Cx43. Red arrows: protein localization. Original magnification, 400x. (C) Kaplan-Meier curves of OS and RFS in NSCLC patients with low vs. high tri-expression of $\alpha$-SMA, Cx43, and LDH-B ( $\mathrm{n}=82$; $\mathrm{P}<0.0001$, log-rank test).

Co-overexpression of $\alpha$-SMA, CX43, and LDH-B predicts poor prognosis in patients with NSCLC

As shown in Fig. 10A, a tree diagram showed that $78.6 \%$ of NSCLC patients with high $\alpha$-SMA and Cx43 levels also demonstrated a high level of LDH-B expression, whereas $35.7 \%$ of patients with low levels of $\alpha$-SMA and Cx43 demonstrated a lower level of LDH-B expression. Moreover, the levels of $\alpha$-SMA, Cx43, and LDH-B were significantly elevated in NSCLC samples compared with matched adjacent noncancerous tissues (Fig. 10B). As shown in Fig. 10B, $\alpha$-SMA was strongly expressed in CAFs but not in cancer cells, whereas LDH-B was significantly expressed in cancer cells but not in tumor stroma. Moreover, $\mathrm{Cx} 43$ was detected at the intercellular boundaries of cancer cells and tumor stroma, and the accumulation of $\alpha$-SMA- and Cx43-positive CAFs was predominantly observed at the invasive front of NSCLC 
lesions, further reinforcing the role of $\mathrm{Cx} 43$ in promoting the effects of CAFs on the aggressive tendencies of NSCLC.

The clinical characteristics of the patients are summarized in Table 2-4. Overall, individual high expression of $\alpha$-SMA, Cx43, or LDH-B was correlated with tumor, node, metastasis (TNM) stage and NSCLC metastasis. No correlation was found between individual high expression of $\alpha$-SMA, Cx43, or LDH-B and other clinical features, such as age, gender, cell type, tumor size, smoking status, or tumor grade. Furthermore, high bi-expression of $\alpha$-SMA and $\mathrm{Cx} 43$ or $\mathrm{Cx} 43$ and LDH-B was strongly associated with TNM stage, while high bi-expression of $\alpha$-SMA and LDH-B was not associated with any clinical characteristics. Interestingly, high tri-expression of $\alpha$-SMA, $\mathrm{Cx} 43$, and LDH-B was also positively associated with TNM stage and NSCLC metastasis. These results suggest that high individual expression or co-expression of $\alpha$-SMA, Cx43, and LDH-B may be required for the metastasis of NSCLC.

In addition, survival analysis showed that individual overexpression of $\alpha$-SMA, Cx43, or LDH-B

Table 2. Clinical Characteristics of $\alpha$-SMA and Cx43 and LDH-B Expression in NSCLC Patients. *: Data represent as mean \pm standard deviation. $\neq$ : Fisher's exact test. \# : Analysis of variance (ANOVA). High: (Expression score $\geq$ median risk score). Low: (Expression score < median risk score). MD: moderate differentiation. WD: well differentiation

\begin{tabular}{|c|c|c|c|c|c|c|c|c|c|}
\hline \multirow{2}{*}{ Factors } & \multicolumn{3}{|c|}{$\alpha$-SMA } & \multicolumn{3}{|c|}{ Cx43 } & \multicolumn{3}{|c|}{ LDH-B } \\
\hline & High n (\%) & Low n (\%) & $p$-value & High n (\%) & Low n (\%) & $p$-value & High n (\%) & Low n (\%) & $p$-value \\
\hline & $\mathrm{N}=43$ & $\mathrm{~N}=39$ & & $\mathrm{~N}=58$ & $\mathrm{~N}=24$ & & $\mathrm{~N}=48$ & $\mathrm{~N}=34$ & \\
\hline Age & $61.1 \pm 8.5^{*}$ & $59.0 \pm 9.5^{*}$ & $0.509 \dagger$ & $61.5 \pm 7.9^{*}$ & $56.8 \pm 10.6^{*}$ & $0.059 \dagger$ & $58.9 \pm 7.9^{*}$ & $61.6 \pm 9.3^{*}$ & $0.188 \dagger$ \\
\hline \multicolumn{10}{|l|}{ Gender } \\
\hline Female & $15(34.9)$ & $14(35.9)$ & $1.000 \ddagger$ & $18(31.0)$ & $11(45.8)$ & $0.216 \ddagger$ & $15(31.2)$ & $14(41.2)$ & $0.482 \ddagger$ \\
\hline Make & $28(65.1)$ & $25(64.1)$ & & $40(69.0)$ & $13(54.2)$ & & $33(68.8)$ & $20(58.8)$ & \\
\hline \multicolumn{10}{|l|}{ Cell type } \\
\hline Adenocarcinoma & $37(86.0)$ & $31(79.5)$ & $0.559 \ddagger$ & $49(84.5)$ & $19(79.2)$ & $0.538 \ddagger$ & $41(85.4)$ & $27(79.4)$ & $0.557 \ddagger$ \\
\hline Others & $6(14.0)$ & $8(20.5)$ & & $9(15.5)$ & $5(20.8)$ & & $7(14.6)$ & $7(20.6)$ & \\
\hline \multicolumn{10}{|l|}{ Size } \\
\hline$\geq 5 \mathrm{~cm}$ & $11(25.6)$ & $14(35.9)$ & $0.345 \ddagger$ & $18(31.0)$ & $7(29.2)$ & $1.000 \ddagger$ & $18(37.5)$ & $7(20.6)$ & $0.144 \ddagger$ \\
\hline$<5 \mathrm{~cm}$ & $32(74.4)$ & $25(64.1)$ & & $40(69.0)$ & $17(70.8)$ & & $30(62.5)$ & $27(79.4)$ & \\
\hline \multicolumn{10}{|l|}{ Smoking status } \\
\hline Yes & 18(41.9) & 19(48.7) & $0.657 \neq$ & $27(46.6)$ & $10(41.7)$ & $0.808 \ddagger$ & $23(47.9)$ & $14(41.2)$ & $0.654 \ddagger$ \\
\hline No & $25(58.1)$ & $20(51.3)$ & & $31(53.4)$ & $14(58.3)$ & & $25(52.1)$ & $20(58.8)$ & \\
\hline \multicolumn{10}{|l|}{ TNM stage } \\
\hline I-II & $21(48.8)$ & $33(84.6)$ & $0.001 \ddagger$ & $32(55.2)$ & $22(91.7)$ & $0.002 \ddagger$ & $35(72.9)$ & 19(55.9) & $0.012 \ddagger$ \\
\hline III-IV & $22(51.2)$ & $6(15.4)$ & & $26(44.8)$ & $2(8.33)$ & & $13(27.1)$ & $15(44.1)$ & \\
\hline \multicolumn{10}{|l|}{ Metastasis } \\
\hline Yes & $29(67.4)$ & $16(41.0)$ & $0.026 \ddagger$ & $38(65.5)$ & $7(29.2)$ & $0.003 \ddagger$ & $32(66.7)$ & $13(38.2)$ & $0.014 \ddagger$ \\
\hline No & $14(32.6)$ & $23(59.0)$ & & $20(34.5)$ & $17(70.8)$ & & $16(33.3)$ & $21(61.8)$ & \\
\hline \multicolumn{10}{|l|}{ Tumor grade } \\
\hline MD & $37(86.0)$ & $34(87.2)$ & $1.000 \ddagger$ & $50(86.2)$ & 21(87.5) & $1.000 \ddagger$ & $39(81.2)$ & $32(94.1)$ & $0.112 \ddagger$ \\
\hline WD & $6(14.0)$ & $5(12.8)$ & & $8(13.8)$ & $3(12.5)$ & & $9(18.8)$ & $2(5.9)$ & \\
\hline
\end{tabular}

Table 3. Clinical Characteristics of Combine $\alpha$-SMA or Cx43 or LDH-B Expression in NSCLC Patients.*: Data represent as mean \pm standard deviation. $\ddagger$ : Fisher's exact test. \# : Analysis of variance (ANOVA). High: (Expression score $\geq$ median risk score). Low: (Expression score < median risk score). MD: moderate differentiation. WD: well differentiation

\begin{tabular}{|c|c|c|c|c|c|c|c|c|c|c|c|c|}
\hline \multirow{2}{*}{ Factors } & \multicolumn{2}{|c|}{$\alpha-\mathrm{SMA}+\mathrm{Cx} 43$} & \multirow[b]{2}{*}{ Others n (\%) } & \multirow[b]{2}{*}{$p$-value } & \multicolumn{3}{|c|}{ Cx43+LDH-B } & \multirow[b]{2}{*}{$p$-value } & \multicolumn{2}{|c|}{$\alpha-S M A+L D H-B$} & \multirow[b]{2}{*}{ Others n (\%) } & \multirow[b]{2}{*}{$p$-value } \\
\hline & High n (\%) & Low n (\%) & & & High n (\%) & Low n (\%) & Others n (\%) & & High n (\%) & Low n (\%) & & \\
\hline & $\mathrm{N}=28$ & $\mathrm{~N}=14$ & $\mathrm{~N}=40$ & & $\mathrm{~N}=32$ & $\mathrm{~N}=10$ & $\mathrm{~N}=40$ & & $\mathrm{~N}=23$ & $\mathrm{~N}=19$ & $\mathrm{~N}=40$ & \\
\hline Age & $53.64 \pm 10.31^{*}$ & $61.07 \pm 7.75^{*}$ & $61.63 \pm 8.61^{*}$ & $0.424 \#$ & $61.25 \pm 6.94 *$ & $60.60 \pm 10.38^{*}$ & $59.00 \pm 10.18^{*}$ & $0.570 \#$ & $60.57 \pm 7.48^{*}$ & $61.58 \pm 9.25^{*}$ & $59.08 \pm 9.78^{*}$ & $0.672 \#$ \\
\hline \multicolumn{13}{|l|}{ Gender } \\
\hline Female & $7(25.0)$ & $7(50.0)$ & $15(37.5)$ & $0.258 \neq$ & $8(25.0)$ & $5(50.0)$ & $16(40.0)$ & $0.245 \ddagger$ & $7(30.4)$ & $10(52.6)$ & $12(30.0)$ & $0.199 \ddagger$ \\
\hline Male & $21(75.0)$ & $7(50.0)$ & $25(62.5)$ & & $24(75.0)$ & $5(50.0)$ & $24(60.0)$ & & $16(69.6)$ & $9(57.4)$ & $28(70.0)$ & \\
\hline \multicolumn{13}{|l|}{ Cell type } \\
\hline Adenocarcinoma & $24(85.7)$ & 11(78.6) & $33(82.5)$ & 0.841 \# & $29(90.6)$ & $9(90.0)$ & $30(75.0)$ & $0.177 \ddagger$ & $19(82.6)$ & $14(73.7)$ & $35(87.5)$ & $0.419 \ddagger$ \\
\hline Others & $4(14.3)$ & $3(21.4)$ & $7(17.5)$ & & $3(9.4)$ & $1(10.0)$ & $10(25.0)$ & & $4(17.4)$ & $5(26.3)$ & $5(12.5)$ & \\
\hline \multicolumn{13}{|l|}{ Size } \\
\hline$\geq 5 \mathrm{~cm}$ & $7(25.0)$ & $5(35.7)$ & $13(32.5)$ & $0.721 \neq$ & $12(37.5)$ & $2(20.0)$ & $11(27.5)$ & 0.489 ; & $8(34.8)$ & $6(31.6)$ & $11(27.5)$ & $0.827 \ddagger$ \\
\hline$<5 \mathrm{~cm}$ & $21(75.0)$ & $9(64.3)$ & $27(67.5)$ & & $20(62.5)$ & $8(80.0)$ & $29(72.5)$ & & $15(65.2)$ & $13(68.4)$ & $29(72.5)$ & \\
\hline \multicolumn{13}{|l|}{ Smoking status } \\
\hline Yes & $13(46.4)$ & $5(35.7)$ & $19(47.5)$ & $0.737 \ddagger$ & $17(53.1)$ & $5(50.0)$ & $15(37.5)$ & $0.394 \ddagger$ & $11(47.8)$ & $7(36.8)$ & $19(47.5)$ & $0.710 \ddagger$ \\
\hline No & $15(53.6)$ & $9(64.3)$ & $21(52.5)$ & & $15(46.9)$ & $5(50.0)$ & $25(62.5)$ & & $12(52.2)$ & $12(63.2)$ & $21(52.5)$ & \\
\hline \multicolumn{13}{|l|}{ TNM stage } \\
\hline I-II & $11(39.3)$ & $14(100.0)$ & $29(72.5)$ & $0.000 \ddagger$ & $14(43.75)$ & $7(70.0)$ & 33(82.5) & $0.003 \ddagger$ & $12(52.2)$ & $14(73.7)$ & $28(70.0)$ & $0.254 \ddagger$ \\
\hline III-IV & $17(60.7)$ & $0(0.0)$ & $11(27.5)$ & & $18(56.25)$ & $3(30.0)$ & $7(17.5)$ & & $11(47.8)$ & $5(26.3)$ & $12(30.0)$ & \\
\hline \multicolumn{13}{|l|}{ Metastasis } \\
\hline Yes & $19(67.9)$ & $6(42.9)$ & $20(50.0)$ & $0.212 \ddagger$ & $20(62.5)$ & $4(40.0)$ & $21(52.5)$ & 0.420 ‡ & $17(73.9)$ & $9(57.4)$ & $19(47.5)$ & $0.096 \ddagger$ \\
\hline No & $9(32.1)$ & $8(57.1)$ & $20(50.0)$ & & $12(37.5)$ & $6(60.0)$ & $19(47.5)$ & & $6(26.1)$ & $10(52.6)$ & $21(52.5)$ & \\
\hline \multicolumn{13}{|l|}{ Tumor grade } \\
\hline MD & $24(85.7)$ & 11(78.6) & $36(90.0)$ & $0.550 \neq$ & $26(81.25)$ & $9(90.0)$ & $36(90.0)$ & $0.526 \ddagger$ & $19(82.6)$ & $17(89.5)$ & $35(87.5)$ & $0.787 \ddagger$ \\
\hline WD & $4(14.3)$ & $3(21.4)$ & $4(10.0)$ & & $6(18.75)$ & $1(10.0)$ & $4(10.0)$ & & $4(17.4)$ & $2(10.5)$ & $5(12.5)$ & \\
\hline
\end{tabular}


significantly decreased overall survival (OS) and relapse-free survival (RFS) in NSCLC patients (Fig. S3A and S3B). High bi-expression of $\alpha$-SMA and Cx43, Cx43 and LDH-B, or $\alpha$-SMA and LDH-B was also associated with lower OS and RFS (Fig. S3C and S3D). Additionally, patients with overexpression of all 3 molecules had the lowest OS and RFS (Fig. 10C). Importantly, univariate and multivariate Cox proportional hazards analysis revealed that only the high tri-expression of $\alpha$-SMA, Cx43, and LDH-B was an independent prognostic factor for OS and RFS in patients with NSCLC (Table 5). Taken together, these findings demonstrate that the combination of $\alpha$-SMA, Cx43, and LDH-B levels predicts poor outcome in NSCLC patients, further supporting the close metabolic coupling between CAFs and NSCLC cells mediated by $\mathrm{Cx} 43$-formed unidirectional GJIC, which results in the malignant progression of NSCLC.

Table 4. Clinical Characteristics of tri-expression of $\alpha$-SMA and Cx 43 and LDH-B in NSCLC Patients. *: Data represent as mean \pm standard deviation. $\neq$ : Fisher's exact test. \# : Analysis of variance (ANOVA). High: (Expression score $\geq$ median risk score). Low: (Expression score < median risk score). MD: moderate differentiation. WD: well differentiation

\begin{tabular}{|c|c|c|c|c|}
\hline Factors & $\alpha-S M A h^{\text {hiCx}} 43^{\text {hiLDH}}-\mathrm{B}^{\text {hi }}$ & $\alpha$-SMAlowCx43bwLDH-Bbw & Others & $p$-value \\
\hline$\alpha-S M A+C x 43+L I$ & $\mathrm{~N}=22$ & $\mathrm{~N}=5$ & $\mathrm{~N}=55$ & \\
\hline Age & $60.7 \pm 7.2^{*}$ & $57.8 \pm 7.3^{*}$ & $60.0 \pm 9.9^{*}$ & $0.858 \#$ \\
\hline \multicolumn{5}{|l|}{ Gender } \\
\hline Female & $7(31.8)$ & $4(80.0)$ & $18(32.7)$ & $0.098 \ddagger$ \\
\hline Male & $15(68.2)$ & $1(20.0)$ & $37(67.3)$ & \\
\hline \multicolumn{5}{|l|}{ Cell type } \\
\hline Adenocarcinome $\bar{c}$ & $19(86.4)$ & $5(100.0)$ & $44(80.0)$ & $0.462 \ddagger$ \\
\hline Others & $3(13.6)$ & $0(0.0)$ & $11(20.0)$ & \\
\hline \multicolumn{5}{|l|}{ Size } \\
\hline$\geq 5 \mathrm{~cm}$ & $8(36.4)$ & $1(20.0)$ & $16(29.1)$ & $0.716 \ddagger$ \\
\hline$<5 \mathrm{~cm}$ & $14(63.6)$ & $4(80.0)$ & $39(70.9)$ & \\
\hline \multicolumn{5}{|l|}{ Smoking status } \\
\hline Yes & $10(45.5)$ & $1(20.0)$ & $26(47.3)$ & $0.502 \ddagger$ \\
\hline No & $12(54.5)$ & $4(80.0)$ & $29(52.7)$ & \\
\hline \multicolumn{5}{|l|}{ TNM stage } \\
\hline I-II & $9(40.9)$ & $5(100.0)$ & $40(72.7)$ & $0.007 \ddagger$ \\
\hline III-IV & $13(59.1)$ & $0(0.0)$ & $15(27.3)$ & \\
\hline \multicolumn{5}{|l|}{ Metastasis } \\
\hline Yes & $17(77.3)$ & $2(40.0)$ & $26(47.3)$ & $0.045 \ddagger$ \\
\hline No & $5(22.7)$ & $3(60.0)$ & 29(52.7) & \\
\hline \multicolumn{5}{|l|}{ Tumor grade } \\
\hline MD & $17(77.3)$ & $4(80.0)$ & $50(90.9)$ & $0.257 \ddagger$ \\
\hline WD & $5(22.7)$ & $1(20.0)$ & $5(9.09)$ & \\
\hline
\end{tabular}

Table 5. Univariate and Multivariate analysis identifies factors influencing overall survival and relapse-free survival rate of NSCLC patients. HR, Hazard ratio; CI, confidence interval. ${ }^{*} P<0.05$

\begin{tabular}{|c|c|c|c|c|c|c|c|c|}
\hline \multirow{3}{*}{ Factors } & \multicolumn{3}{|c|}{ overall survival rate } & \multicolumn{5}{|c|}{ rehpse-free survival rate } \\
\hline & \multirow{2}{*}{$\begin{array}{l}\text { Univariate analysis } \\
\text { HR }(95 \% \mathrm{Cl})\end{array}$} & \multirow[b]{2}{*}{$p$-value } & \multirow{2}{*}{$\begin{array}{l}\text { Multivariate analysis } \\
\text { HR }(95 \% \mathrm{CI})\end{array}$} & \multicolumn{2}{|r|}{ Univariate analysis } & \multicolumn{3}{|c|}{ Multivariate analysis } \\
\hline & & & & $p$-value & HR $(95 \%$ Cl) & $p$-value & HR $(95 \%$ Cl) & $p$-value \\
\hline Age & $1.051(1.001-1.118)$ & $0.047^{*}$ & $1.123(1.050-1.202)$ & $0.001^{*}$ & $1.027(0.970-1.087)$ & 0.358 & & \\
\hline Gender & $1.509(0.535-4.255)$ & 0.437 & & & $1.375(0.437-4.329)$ & 0.586 & & \\
\hline Cell type & $0.466(0.106-2.040)$ & 0.311 & & & $0.765(0.215-2.723)$ & 0.679 & & \\
\hline Size & $1.361(0.471-3.931)$ & 0.569 & & & $1.185(0.396-3.543)$ & 0.762 & & \\
\hline Smoking status & $1.361(0.524-3.534)$ & 0.527 & & & $0.878(0.316-2.441)$ & 0.803 & & \\
\hline TNM stage & $2.715(1.046-7.049)$ & $0.040^{*}$ & $1.000(0.319-3.131)$ & 0.999 & $4.744(1.614-13.947)$ & $0.005^{*}$ & $1.078(0.333-3.489)$ & 0.900 \\
\hline Metastasis & $3.858(1.116-13.345)$ & $0.033^{*}$ & $1.947(0.513-7.397)$ & 0.328 & $3.578(1.112-11.509)$ & $0.032^{*}$ & $1.801(0.563-5.762)$ & 0.321 \\
\hline Tumor grade & $0.486(0.064-3.666)$ & 0.484 & & & $3.199(1.014-10.095)$ & $0.047 *$ & $10.661(2.483-45.777)$ & $0.001^{*}$ \\
\hline$\alpha$-SMA expression & $7.639(1.744-33.459)$ & $0.007^{*}$ & $5.974(0.712-50.130)$ & 0.100 & $7.725(2.255-26.456)$ & $0.001^{*}$ & $4.019(0.892-18.106)$ & 0.070 \\
\hline Cx43 expression & $8.514(1.127-64.347)$ & $0.038^{*}$ & $0.007(0.000-0.714)$ & $0.035^{*}$ & $12.848(1.668-98.954)$ & $0.014^{*}$ & $1.407(0.261-7.583)$ & 0.691 \\
\hline LDH-B expression & $6.954(1.584-30.534)$ & $0.010^{*}$ & $11.446(1.400-93.548)$ & $0.023^{*}$ & $4.833(1.088-21.464)$ & $0.038^{*}$ & $1.228(0.307-4.907)$ & 0.772 \\
\hline$\alpha-\mathrm{SMA}+\mathrm{C} \times 43$ & $0.850(0.461-1.569)$ & 0.604 & & & $1.032(0.609-1.474)$ & 0.908 & & \\
\hline Cx43+LDH-B & $0.659(0.356-1.219)$ & 0.184 & & & $0.798(0.457-1.393)$ & 0.426 & & \\
\hline$\alpha-S M A+L D H-B$ & $0.890(0.502-1.578)$ & 0.690 & & & $0.993(0.587-1.678)$ & 0.978 & & \\
\hline$\alpha-S M A+C \times 43+L D H-B$ & $9.484(2.164-41.562)$ & $0.003^{*}$ & $712.482(13.853-36645.246)$ & $0.001^{*}$ & $13.116(2.913-59.056)$ & $0.001^{*}$ & $18.291(4.161-80.409)$ & $0.000^{*}$ \\
\hline
\end{tabular}




\section{Cellular Physiology Cell Physiol Biochem 2018;51:315-336 \begin{tabular}{ll|l} 
and Biochemistry Published onlıne: 17/November 2018 & $\begin{array}{l}\text { (c) } 2018 \text { The Author(s). Published by S. Karger AG, Basel } \\
\text { www.karger.com/cpb }\end{array}$ \\
\hline
\end{tabular} \\ Luo et al.: Cafs Accelerate NSCLC Malignant Progression}

\section{Discussion}

Here, we present evidence that an important role for $\mathrm{Cx} 43$-formed unidirectional GJIC in mediating metabolic cooperation between CAFs and NSCLC cells. NSCLC cells enhance OXPHOS upon stimulation of aerobic glycolytic CAFs to facilitate malignant progression, mainly through the ATP-activated PI3K/Akt and MAPK/ERK signaling pathways. These findings are also supported by a significant correlation between the high tri-expression of $\alpha$-SMA, Cx43, and LDH-B and poor prognosis in NSCLC patients.

Although considerable evidence supports a role for connexins as tumor suppressors, an increasing number of studies have highlighted the facilitating role of connexins in specific stages of malignant progression in some types of cancer through both GJIC-dependent and -independent mechanisms $[13,15,18]$. In particular, Cx43-mediated heterocellular GJIC between cancer cells and their surrounding cells have been reported to promote metastasis in human gastric cancer [21], prostate cancer [22], and glioma [23]. In the present study, we demonstrated that GJIC was formed not only among CAFs or NSCLC cells themselves (homocellular GJIC) but also from CAFs to NSCLC cells (heterocellular GJIC), while the lack of GJIC from NSCLC cells to CAFs suggests that asymmetric unidirectional GJIC is present from CAFs to NSCLC cells. According to a previously reported hypothesis [44], the formation of asymmetric unidirectional GJIC may be due to malignant transformation, which involves some alterations in cell communication patterns. Importantly, the formation of functional GJIC is known to require the integration of connexins into the plasma membrane [45]. Indeed, we found that only Cx43 was successfully integrated into the plasma membrane of both CAFs and NSCLC cells. Consistent with this, $\mathrm{Cx} 43$ was predominantly expressed at the intercellular boundaries of cancer cells and tumor stroma, especially at the invasive front. Moreover, blocking CAF-NSCLC unidirectional GJIC by $18 \alpha$-GA or Cx43 knockdown had the same effect of inhibiting the aggressive behavior of co-cultured NSCLC cells. In contrast, enhancing GJIC by RA or $\mathrm{Cx} 43$ overexpression had the opposite effect of promoting this aggressive behavior. In addition, the simultaneous inhibition of unidirectional GJIC and glycolysis in CAFs further reduced the EMT phenotype and migratory and invasive potential of NSCLC cells, while the simultaneous enhancement of GJIC and glycolysis further reinforced the aggressiveness of NSCLC cells. However, enhancement of glycolysis in CAFs failed to restore the impaired aggressiveness of GJIC-blocked NSCLC cells, while inhibition of glycolysis partially reversed the increased aggressiveness of GJIC-enhanced NSCLC cells. Therefore, our results indicate that $\mathrm{Cx} 43$ mediates the functional CAF-NSCLC GJIC and is mainly responsible for the aggressive tendencies of NSCLC.

It is now becoming clear that intricate interactions, including metabolic coupling, between cancer cells and CAFs are critical for the development and progression of cancer $[10,46,47]$. Indeed, in this study, we found that CAFs enhanced the migratory and invasive potential of co-cultured A549 and H1299 cells by inducing EMT. Meanwhile, CAFs underwent aerobic glycolysis upon their interplay with these NSCLC cells. In contrast, A549 and H1299 cells shifted their metabolism to OXPHOS in response to CAF stimulation. Although the occurrence of the Warburg effect in cancer cells was first proposed by Otto H. Warburg in the early 1920s [8], in 2008, Vincent et al. demonstrated that skin myofibroblasts experience aerobic glycolysis exactly like cancer cells [48]. Furthermore, Lisanti et al. revealed that caveolin-1-deficient CAFs show the upregulation of both myofibroblast markers and glycolytic enzymes under normoxic conditions and this was associated with the recurrence, metastasis, and poor outcome of human breast cancer [9]. Recently, Fiaschi et al. found that CAFs shift their metabolism toward a Warburg phenotype, while prostate cancer cells are reprogrammed toward aerobic metabolism to sustain their energetic needs and growth [10]. Our results are consistent with the new hypothesis of the reverse Warburg effect, in which NSCLC cells induced aerobic glycolysis in neighboring CAFs, in turn, CAFs stimulated NSCLC cells to enhance OXPHOS, and therefore NSCLC cells obtained higher migratory and invasive ability. It is known that GJIC mediates not only intercellular communication but also metabolic coupling between adjacent cells [26, 27]. Interestingly, we herein demonstrated 
that metabolic cooperation between CAFs and NSCLC cells was under strict control of Cx43-formed unidirectional GJIC, with our data indicating that GJIC inhibition by Cx43 knockdown caused reduced OXPHOS in co-cultured NSCLC cells, while GJIC enhancement by $\mathrm{Cx} 43$ overexpression resulted in enhanced OXPHOS in these NSCLC cells. Moreover, dual suppression of unidirectional GJIC and glycolysis in CAFs further reduced OXPHOS in NSCLC cells, while dual enhancement of GJIC and glycolysis in CAFs further enhanced OXPHOS in NSCLC cells. Therefore, our findings support a key role for Cx43-formed unidirectional GJIC in mediating intercellular metabolic cooperation between NSCLC cells and CAFs.

Previous studies have demonstrated that several nucleotides (particularly ATP and ADP) and glucose and its metabolites, including glucose-6-phosphate and lactate, can be transmitted through Cx43-formed channels $[49,50]$. Recently, Chen et al. confirmed that metastatic brain cancer cells employ Cx43-composed GJIC to transfer cGAMP to astrocytes, thereby supporting tumor growth and chemoresistance [24]. In the present study, we observed that blocking GJIC did not fully reverse the CAF-facilitated effects on OXPHOS and the migration and invasion of NSCLC cells. Suppression of glycolysis still further weakened OXPHOS and malignant characteristics in GJIC-blockaded NSCLC cells. Therefore, we cannot fully exclude the possible involvement of other intercellular communication modes (such as exosomes) in metabolic coupling between CAFs and NSCLC cells.

Considerable evidence has indicated that the PI3K/Akt and MAPK/ERK pathways contribute significantly to tumor cell EMT and invasion and metastasis [51]. Here, we found that activation of the PI3K/Akt and MAPK/ERK cascades in NSCLC cells was mainly due to CAF stimulation by a GJIC-dependent mechanism. The addition of exogenous ATP greatly activated the PI3K/Akt and MAPK/ERK pathways and promoted the migration and invasion of these NSCLC cells. In contrast, inhibition of PI3K/Akt or MAPK/ERK activity by LY294002 or U0126 resulted in a similar decrease in the migratory and invasive potential of NSCLC cells. Combined inhibition of the PI3K/Akt and MAPK/ERK pathways caused a synergetic reduction in the migration and invasion of NSCLC cells. Furthermore, the inhibitory effects of LY294002 and/or U0126 on PI3K/Akt and MAPK/ERK activity and the aggressiveness of NSCLC cells were partially antagonized by the addition of exogenous ATP. ATP has been shown to activate multiple signal transduction pathways (e.g., PI3K/Akt and ERK1/2) and is positively associated with cancer migration and invasion [52]. Therefore, our findings suggest that ATP from increased OXPHOS is deeply involved in the CAF-stimulated activation of the PI3K/Akt and MAPK/ERK pathways, thus promoting the malignant behavior of NSCLC cells.

Although most previous studies of prognostic factors focused on cancer cells, some recent studies highlighted the importance of CAFs in predicting cancer metastasis and poor clinical outcome. For example, an 11-gene prognostic CAF signature, including ICAM1, THBS2, and B3GALT2, is associated with the survival of patients with NSCLC [30]. Podoplanin expression [53] or the lack of stromal Cav-1 [9] in CAFs is positively correlated with poor prognosis of lung adenocarcinoma or breast cancer, respectively. Here, we found the levels of $\alpha$-SMA in CAFs, LDH-B in NSCLC cells, and Cx43 in both CAFs and NSCLC cells as important prognostic markers for primary NSCLC patients. High individual expression or co-expression of $\alpha$-SMA, Cx43, and LDH-B was strongly correlated with metastasis, OS, and RFS in NSCLC patients. More importantly, only the high tri-expression of $\alpha$-SMA, Cx43, and LDH-B was an independent prognostic factor for OS and RFS in NSCLC patients. Therefore, our results indicate that $\alpha$-SMA, Cx43, and LDH-B can serve as novel prognostic markers for primary NSCLC patients. 


\section{Cellular Physiology Cell Physiol Biochem 2018;51:315-336 and Biochemistry Publis.1159/000495232 $\begin{aligned} & \text { DO } 2018 \text { The Author(s). Published by S. Karger AG, Basel } \\ & \text { www.karger.com/cpb }\end{aligned}$

Luo et al.: Cafs Accelerate NSCLC Malignant Progression

\section{Conclusion}

Our study reveals a novel role for $\mathrm{Cx} 43$-formed unidirectional GJIC in mediating metabolic coupling between CAFs and NSCLC cells and thereby facilitating malignant progression of NSCLC. Glycolytic CAFs contribute to the EMT, migration, and invasion of NSCLC cells mainly by enhancing OXPHOS and increasing ATP-activated PI3K/Akt and MAPK/ERK signaling in a GJIC-dependent manner. These findings are also supported by a strongly positive correlation between the high tri-expression of $\alpha$-SMA, Cx43, and LDH-B and poor prognosis of NSCLC patients. Despite the need for further studies to explore the complex mechanisms underlying the role of $\mathrm{Cx} 43$-formed unidirectional GJIC in the CAF-facilitated aggressive biological behavior of NSCLC, our findings provide evidence that unidirectional GJIC and its constitutive protein $\mathrm{Cx} 43$ may be attractive targets for new therapeutic interventions against the malignant progression of NSCLC.

\section{Acknowledgements}

This work was supported by the National Natural Science Foundation of China (No. 81460447 and No. 81860649) and the Project of Innovation, Entrepreneurship, and Joint Training Base for Pharmaceutical Postgraduates. The first batch of cultivating talents of young and middle-aged backbone teachers in Guangxi universities. This research was funded by Gunagxi First-class Discipline Project for Pharmaceutical Sciences (No. GXFCDP-PS-2018).

\section{Disclosure Statement}

The authors declare no conflict of interests.

\section{References}

1 Ferlay J,Soerjomataram I,Dikshit R,Eser S,Mathers C,Rebelo M,Parkin DM,Forman D,Bray F: Cancer incidence and mortality worldwide: sources, methods and major patterns in GLOBOCAN 2012. Int J Cancer 2015;136:E359-386.

2 Reck M, Heigener DF, Mok T, Soria JC, Rabe KF: Management of non-small-cell lung cancer: recent developments. Lancet 2013;382:709-719.

Siegel RL, Miller KD, Jemal A: Cancer statistics, 2016. Ca Cancer J Clin 2016;66:7-30.

4 Bremnes RM, Donnem T, Al-Saad S, Al-Shibli K, Andersen S, Sirera R, Camps C, Marinez I, Busund LT: The role of tumor stroma in cancer progression and prognosis: emphasis on carcinoma-associated fibroblasts and non-small cell lung cancer. J Thorac Oncol 2011;6:209-217.

5 Giannoni E, Bianchini F, Masieri L, Serni S, Torre E, Calorini L, Chiarugi P: Reciprocal activation of prostate cancer cells and cancer-associated fibroblasts stimulates epithelial-mesenchymal transition and cancer stemness. Cancer Res 2010;70:6945-6956.

-6 Yu Y, Xiao CH, Tan LD, Wang QS, Li XQ, Feng YM: Cancer-associated fibroblasts induce epithelialmesenchymal transition of breast cancer cells through paracrine TGF-beta signalling. Br J Cancer 2014;110:724-732.

7 Neri S, Ishii G, Hashimoto H, Kuwata T, Nagai K, Date H, Ochiai A: Podoplanin-expressing cancer-associated fibroblasts lead and enhance the local invasion of cancer cells in lung adenocarcinoma. Int J Cancer 2015;137:784-796.

8 Warburg 0: On the origin of cancer cells. Science 1956;123:309-314.

-9 Pavlides S, WhitakerMD, CastelloCR, Flomenberg N, Witkiewicz AK, Frank PG, Casimiro MC, Wang C, Fortina P, Addya S, Pestell RG, Martinez-Outschoorn UE, Sotgia F, Lisanti MP: The reverse Warburg effect: aerobic glycolysis in cancer associated fibroblasts and the tumor stroma. Cell Cycle 2009;8:3984-4001. 


\section{Cellular Physiology Cell Physiol Biochem 2018;51:315-336

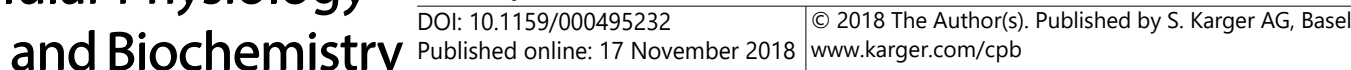

Luo et al.: Cafs Accelerate NSCLC Malignant Progression

10 Fiaschi T, Marini A, Giannoni E, Taddei ML, Gandellini P, De Donatis A, Lanciotti M, Serni S, Cirri P, Chiarugi P: Reciprocal metabolic reprogramming through lactate shuttle coordinately influences tumor-stroma interplay. Cancer Res 2012;72:5130-5140.

-11 Zhao H, Yang L, Baddour J, Achreja A, Bernard V, Moss T, Marini JC, Tudawe T, Seviour EG, San Lucas FA, Alvarez H, Gupta S, Maiti SN, Cooper L, Peehl D, Ram PT, Maitra A, Nagrath D: Tumor microenvironment derived exosomes pleiotropically modulate cancer cell metabolism. Elife 2016;5:e10250.

12 Yamasaki H, Naus CC: Role of connexin genes in growth control. Carcinogenesis 1996;17:1199-1213.

-13 Aasen T, Mesnil M, Naus CC, Lampe PD, Laird DW: Gap junctions and cancer: communicating for 50 years. Nat Rev Cancer 2016;16:775-788.

14 Harris AL: Connexin channel permeability to cytoplasmic molecules. Prog Biophys Mol Biol 2007;94:120143.

15 Naus CC, Laird DW: Implications and challenges of connexin connections to cancer. Nat Rev Cancer 2010;10:435-441.

16 Mesnil M, Crespin S, Avanzo JL, Zaidan-Dagli ML: Defective gap junctional intercellular communication in the carcinogenic process. Biochim Biophys Acta 2005;1719:125-145.

17 Hirschi KK, Xu CE, Tsukamoto T, Sager R: Gap junction genes Cx26 and Cx43 individually suppress the cancer phenotype of human mammary carcinoma cells and restore differentiation potential. Cell Growth Differ 1996; 7:861-870.

18 Cronier L, Crespin S, Strale PO, Defamie N, Mesnil M: Gap junctions and cancer: new functions for an old story. Antioxid Redox Signal 2009;11:323-338.

19 SaitoKM, Asada H, Niizeki H, Katoh F, Masuzawa M, Tsutsumi M, Kuniyasu H, Ito A, Nojima H, Miyagawa S: Role for connexin 26 in metastasis of human malignant melanoma: communication between melanoma and endothelial cells via connexin 26. Cancer 2007;110:1162-1172.

-20 Ito A, Katoh F, Kataoka TR, Okada M, Tsubota N, Asada H, Yoshikawa K, Maeda S, Kitamura Y, Yamasaki H, Nojima H: A role for heterologous gap junctions between melanoma and endothelial cells in metastasis. J Clin Invest 2000;105:1189-1197.

-21 Tang B, Peng ZH, Yu PW, Yu G, Qian F, Zeng DZ, Zhao YL, Shi Y, Hao YX, Luo HX: Aberrant expression of Cx43 is associated with the peritoneal metastasis of gastric cancer and $\mathrm{Cx} 43$-mediated gap junction enhances gastric cancer cell diapedesis from peritoneal mesothelium. Plos One 2013;8:e74527.

22 Lamiche C, Clarhaut J, Strale PO, Crespin S, Pedretti N, Bernard FX, Naus CC, Chen VC, Foster LJ, Defamie N, Mesnil M, Debiais F, Cronier L: The gap junction protein Cx43 is involved in the bone-targeted metastatic behaviour of human prostate cancer cells. Clin Exp Metastasis 2012;29:111-122.

23 Hong X, Sin WC, Harris AL, Naus CC: Gap junctions modulate glioma invasion by direct transfer of microRNA. Oncotarget 2015;6:15566-15577.

24 Chen Q Boire A, Jin X, Valiente M, Er EE, LopezSA, Jacob LS, Patwa R, Shah H, Xu K, Cross JR, Massague J: Carcinoma-astrocyte gap junctions promote brain metastasis by cGAMP transfer. Nature 2016;533:493498.

25 Zhang ZQ Hu Y, Wang BJ, Lin ZX, Naus CC, Nicholson BJ: Effective asymmetry in gap junctional intercellular communication between populations of human normal lung fibroblasts and lung carcinoma cells. Carcinogenesis 2004;25:473-482.

-26 SubakSH, Burk RR, Pitts JD: Metabolic co-operation between biochemically marked mammalian cells in tissue culture. J Cell Sci 1969;4:353-367.

27 Gilula NB, Reeves OR, Steinbach A: Metabolic coupling, ionic coupling and cell contacts. Nature 1972;235:262-265.

28 Chaudhri VK, Salzler GG, Dick SA, Buckman MS, Sordella R, Karoly ED, Mohney R, Stiles BM, Elemento O, Altorki NK, McGraw TE: Metabolic alterations in lung cancer-associated fibroblasts correlated with increased glycolytic metabolism of the tumor. Mol Cancer Res 2013;11:579-592.

29 Horie M, Saito A, Mikami Y, Ohshima M, Morishita Y, Nakajima J, Kohyama T, Nagase T: Characterization of human lung cancer-associated fibroblasts in three-dimensional in vitro co-culture model. Biochem Biophys Res Commun 2012;423:158-163.

30 Navab R, Strumpf D, Bandarchi B, Zhu CQ Pintilie M, Ramnarine VR, Ibrahimov E, Radulovich N, Leung L, Barczyk M, Panchal D, To C, Yun JJ, Der S, Shepherd FA, Jurisica I, Tsao MS: Prognostic gene-expression signature of carcinoma-associated fibroblasts in non-small cell lung cancer. Proc Natl Acad Sci USA 2011;108:7160-7165. 


\section{Cellular Physiology Cell Physiol Biochem 2018;51:315-336

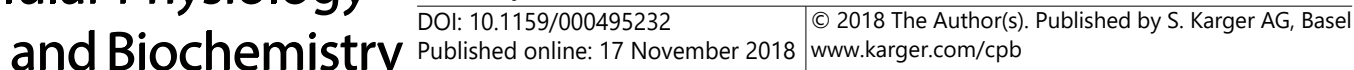

Luo et al.: Cafs Accelerate NSCLC Malignant Progression

-31 Ishii G, Hashimoto H, Asada K, Ito T, Hoshino A, Fujii S, Kojima M, Kuwata T, Harigaya K,Nagai K, Ushijima T, Ochiai A: Fibroblasts associated with cancer cells keep enhanced migration activity after separation from cancer cells: a novel character of tumor educated fibroblasts. Int J Oncol 2010;37:317-325.

-32 Yang J, Qin G, Luo M, Chen J, Zhang Q, Li L, Pan L, Qin S: Reciprocal positive regulation between Cx26 and PI3K/Akt pathway confers acquired gefitinib resistance in NSCLC cells via GJIC-independent induction of EMT. Cell Death Dis 2015;6:e1829.

33 Qin G, Luo M, Chen J, Dang Y, Chen G, Li L, Zeng J, Lu Y, Yang J: Reciprocal activation between MMP-8 and TGF-beta1 stimulates EMT and malignant progression of hepatocellular carcinoma. Cancer Lett 2016;374:85-95.

34 Liu B, Wang G, Yang J, Pan X, Yang Z, Zang L: Berberine inhibits human hepatoma cell invasion without cytotoxicity in healthy hepatocytes. Plos One 2011;6:e21416.

-35 Yamaguchi J, Kusano KF, Masuo O, Kawamoto A, Silver M, Murasawa S, BoschMM, Masuda H, Losordo DW, Isner JM, Asahara T: Stromal cell-derived factor-1 effects on ex vivo expanded endothelial progenitor cell recruitment for ischemic neovascularization. Circulation 2003;107:1322-1328.

-36 Chen Y, Zou L, Zhang Y, Chen Y, Xing P, Yang W, Li F, Ji X, Liu F, Lu X: Transforming growth factor-beta1 and alpha-smooth muscle actin in stromal fibroblasts are associated with a poor prognosis in patients with clinical stage I-IIIA nonsmall cell lung cancer after curative resection. Tumour Biol 2014;35:6707-6713.

-37 Lu R, Jiang M, Chen Z, Xu X, Hu H, Zhao X, Gao X, Guo L: Lactate dehydrogenase 5 expression in NonHodgkin lymphoma is associated with the induced hypoxia regulated protein and poor prognosis. Plos One 2013;8:e74853.

-38 Sulkowska U, Febp AW, Sulkowski S: Association of STAT3 with Cx26 and Cx43 in human uterine endometrioid adenocarcinoma. Oncol Lett 2016;11:4134-4138.

-39 Sotgia F, WhitakerMD, Martinez-Outschoorn UE, Flomenberg N, Birbe RC, Witkiewicz AK, Howell A, Philp NJ, Pestell RG, Lisanti MP: Mitochondrial metabolism in cancer metastasis: visualizing tumor cell mitochondria and the "reverse Warburg effect" in positive lymph node tissue. Cell Cycle 2012;11:14451454.

40 Chen J, Xie J, Jiang Z, Wang B, Wang Y, Hu X: Shikonin and its analogs inhibit cancer cell glycolysis by targeting tumor pyruvate kinase-M2. Oncogene 2011;30:4297-4306.

41 Leithe E, Sirnes S, Omori Y, Rivedal E: Downregulation of gap junctions in cancer cells. Crit Rev Oncog 2006;12:225-256.

42 Bonuccelli G, WhitakerMD, CastelloCR, Pavlides S, Pestell RG, Fatatis A, Witkiewicz AK, Vander Heiden MG, Migneco G, Chiavarina B, Frank PG, Capozza F, Flomenberg N, Martinez-Outschoorn UE, Sotgia F, Lisanti MP: The reverse Warburg effect: glycolysis inhibitors prevent the tumor promoting effects of caveolin-1 deficient cancer associated fibroblasts. Cell Cycle 2010;9:1960-1971.

43 Tabernero A, Medina JM, Giaume C: Glucose metabolism and proliferation in glia: role of astrocytic gap junctions. J Neurochem 2006;99:1049-1061.

-44 Fentiman IS, TaylorPJ: Cultured human breast cancer cells lose selectivity in direct intercellular communication. Nature 1977;269:156-158.

-45 Willecke K, Eiberger J, Degen J, Eckardt D, Romualdi A, Guldenagel M, Deutsch U, Sohl G: Structural and functional diversity of connexin genes in the mouse and human genome. Biol Chem 2002;383:725-737.

-46 Rattigan YI, Patel BB, Ackerstaff E, Sukenick G, Koutcher JA, Glod JW, Banerjee D: Lactate is a mediator of metabolic cooperation between stromal carcinoma associated fibroblasts and glycolytic tumor cells in the tumor microenvironment. Exp Cell Res 2012;318:326-335.

-47 Giannoni E, Taddei ML, Morandi A, Comito G, Calvani M, Bianchini F, Richichi B, Raugei G, Wong N, Tang D, Chiarugi P: Targeting stromal-induced pyruvate kinase M2 nuclear translocation impairs oxphos and prostate cancer metastatic spread. Oncotarget 2015;6:24061-24074.

48 Vincent AS, Phan TT, Mukhopadhyay A, Lim HY, Halliwell B, Wong KP: Human skin keloid fibroblasts display bioenergetics of cancer cells. J Invest Dermatol 2008;128:702-709.

49 Goldberg GS, Lampe PD, Nicholson BJ: Selective transfer of endogenous metabolites through gap junctions composed of different connexins. Nat Cell Biol 1999;1:457-459.

-50 Tabernero A, Giaume C, Medina JM: Endothelin-1 regulates glucose utilization in cultured astrocytes by controlling intercellular communication through gap junctions. Glia 1996;16:187-195. 
Luo et al.: Cafs Accelerate NSCLC Malignant Progression

51 Saxena NK, Sharma D, Ding X, Lin S, Marra F, Merlin D, Anania FA: Concomitant activation of the JAK/ STAT, PI3K/AKT, and ERK signaling is involved in leptin-mediated promotion of invasion and migration of hepatocellular carcinoma cells. Cancer Res 2007;67:2497-2507.

52 Heo JS, Han HJ: ATP stimulates mouse embryonic stem cell proliferation via protein kinase C, phosphatidylinositol 3-kinase/Akt, and mitogen-activated protein kinase signaling pathways. Stem Cells 2006;24:2637-2648.

53 Kawase A, Ishii G, Nagai K, Ito T, Nagano T, Murata Y, Hishida T, Nishimura M, Yoshida J, Suzuki K, Ochiai A: Podoplanin expression by cancer associated fibroblasts predicts poor prognosis of lung adenocarcinoma. Int J Cancer 2008;123:1053-1059. 